\begin{tabular}{|c|c|}
\hline Title & Middlemen margins and globalization \\
\hline \multicolumn{2}{|l|}{ Sub Title } \\
\hline Author & $\begin{array}{l}\text { Bardhan, Pranab(Tsumagari, Masatoshi) } \\
\text { Mookherjee, Dilip } \\
\text { 津曲, 正俊 }\end{array}$ \\
\hline Publisher & Keio Economic Society, Keio University \\
\hline Publication year & 2010 \\
\hline Jtitle & Keio Economic Society discussion paper series Vol.10, No.4 (2010. ) \\
\hline \multicolumn{2}{|l|}{ JaLC DOI } \\
\hline Abstract & $\begin{array}{l}\text { We develop a theory of trading middlemen or entrepreneurs who perform financing, quality } \\
\text { supervision and marketing roles for goods produced by suppliers or workers. Brand-name } \\
\text { reputations are necessary to overcome product quality moral hazard problems; middlemen } \\
\text { margins represent reputational incentive rents. We develop a two sector North-South model of } \\
\text { competitive equilibrium, with endogenous sorting of agents with heterogenous entrepreneurial } \\
\text { abilities into sectors and occupations. The South has a comparative advantage in the more labor } \\
\text { intensive good which is subject to a greater moral hazard problem. Trade liberalization raises } \\
\text { inequality between Southern export sector suppliers and middlemen. Northern middlemen have } \\
\text { incentives to offshore production to the South. The distributive effects of such offshoring tend to } \\
\text { be the opposite of trade liberalization. }\end{array}$ \\
\hline \multicolumn{2}{|r|}{ (i } \\
\hline Genre & Technical Report \\
\hline URL & $\begin{array}{l}\text { https://koara.lib.keio.ac.jp/xoonips/modules/xoonips/detail.php?koara_id=AA10715850-0000100 } \\
\text { 4-0001 }\end{array}$ \\
\hline
\end{tabular}

慶應義塾大学学術情報リポジトリ(KOARA)に揭載されているコンテンッの著作権は、それぞれの著作者、学会または出版社/発行者に帰属し、その権利は著作権法によって 保護されています。引用にあたっては、著作権法を遵守してご利用ください。

The copyrights of content available on the KeiO Associated Repository of Academic resources (KOARA) belong to the respective authors, academic societies, or publishers/issuers, and these rights are protected by the Japanese Copyright Act. When quoting the content, please follow the Japanese copyright act. 
KESDP No. 10-4

Middlemen Margins and Globalization

Pranab Bardhan, Dilip Mookherjee and

Masatoshi Tsumagari 


\title{
MIDDLEMEN MARGINS AND GLOBALIZATION $^{1}$
}

\author{
Pranab Bardhan ${ }^{2}$, Dilip Mookherjee ${ }^{3}$ and Masatoshi \\ Tsumagari $^{4}$
}

This version: March 21, 2010

\begin{abstract}
We develop a theory of trading middlemen or entrepreneurs who perform financing, quality supervision and marketing roles for goods produced by suppliers or workers. Brand-name reputations are necessary to overcome product quality moral hazard problems; middlemen margins represent reputational incentive rents. We develop a two sector North-South model of competitive equilibrium, with endogenous sorting of agents with heterogenous entrepreneurial abilities into sectors and occupations. The South has a comparative advantage in the more labor intensive good which is subject to a greater moral hazard problem. Trade liberalization raises inequality between Southern export sector suppliers and middlemen. Northern middlemen have incentives to offshore production to the South. The distributive effects of such offshoring tend to be the opposite of trade liberalization.
\end{abstract}

Keywords: middlemen, reputation, inequality, trade liberalization, NorthSouth trade; JEL Classification Nos: D33, F12, F13, F21

\footnotetext{
${ }^{1}$ Mookherjee's research was supported by National Science Foundation grant SES0617874. We thank Stefania Garetto, Gordon Hanson, Eric Verhoogen, Jon Vogel, Arnaud Costinot and seminar participants at Columbia, MIT, IFPRI, Namur and Yale for useful comments.

${ }^{2}$ Department of Economics, University of California, Berkeley, CA 94720

${ }^{3}$ Department of Economics, Boston University, 270 Bay State Road, Boston MA 02215

${ }^{4}$ Department of Economics, Keio University, 2-15-45 Mita Minato-ku Tokyo
} 


\section{Introduction}

\subsection{Background and Motivation}

Most trade theory is based on production cost differences across countries. The role of endogenous non-production costs and intermediary markups has not received comparable emphasis. This paper presents a model of middlemen in international trade. In our model, middlemen play two sets of roles: (a) a managerial role encompassing financing, supervision and marketing essential to organize production and transform produced goods into marketable commodities; and (b) a brand-name reputation role, necessary to assure customers about product quality. Our model relies on heterogeneity among agents in the economy with regard to underlying managerial skill. The theory applies equally well to entrepreneurs who supply skilled labor and employ unskilled workers, as well as to middlemen who operate as intermediaries between customers and producers.

In what follows, we interchangeably refer to these intermediaries as entrepreneurs, managers or middlemen. For semantic convenience we use the entrepreneurial interpretation for most part, but a straightforward translation applies to the case of middlemen. We postulate the production function for any good to depend on amounts of 'unskilled' labor or production hours hired by entrepreneurs, and the extent of 'skilled' labor (or managerial inputs) provided by the entrepreneurs themselves. The latter is a shorthand for the value-added management activities self-supplied by the entrepreneurs to their own businesses, as in the Lucas (1978) theory of size distribution of firms based on varying abilities of managers. An alternative interpretation is the effect of capital market imperfections which create borrowing constraints, as in theories of occupational choice of Banerjee and Newman (1993) or Galor and Zeira (1993). In this interpretation, the entrepreneur's 'skill' reflects the wealth of the entrepreneur, which affects the cost of financing the firm's operations since wealthier entrepreneurs have superior access to finance when capital markets are imperfect. Entrepreneurial rents or 'middleman margins' reflect returns to these value-added activities as well as reputational rents.

We are motivated by recent empirical estimates concerning the large proportion of consumer prices accounted by middlemen margins for goods exported by developing to developed countries. Feenstra (1998) provides the following illustration: a Barbie doll sold to US customers for $\$ 10$ returns 35 cents to Chinese labor, 65 cents covers the cost of materials, and $\$ 1$ for 
transportation, profits and overhead in Hong Kong. Mattel, the US retailer earns at least $\$ 1$ per doll. The remaining covers transportation, marketing, wholesaling and retailing in the U.S. Morisset (1998) reports that the price of coffee declined $18 \%$ on world markets but increased $240 \%$ for consumers in the US between 1975-93. The average margin between US consumer price and world price for beef, coffee, oil, rice, sugar and wheat increased by $83 \%$ between 1975-94. Feenstra and Hanson (2004) calculate Hong Kong markups on re-exports of Chinese goods at $12 \%$ of its GDP, while manufacturing accounted for only $6 \%$. The average markup rate accruing to Hong Kong intermediaries on re-exported Chinese goods was 24\%. Ahn, Khandewal and Wei (2009) report that in the early 1980s, 300 trading firms accounted for $80 \%$ of all Japanese trade, with the ten largest accounting for $30 \%$. In China they report that trading firms currently account for $22 \%$ of exports and $18 \%$ of imports.

There are also indications that these middlemen margins accounted for limited pass-through of benefits of trade liberalization to ultimate producers. Fafchamps and Hill (2008) show that increased export prices of Ugandan coffee during 2002-03 was accompanied by rising wholesale prices and a rising gap between wholesale and farmgate prices. This could not be explained by accompanying changes in transport or storage costs. In similar vein, McMillan, Rodrik and Welch (2002) showed that at most 40-50\% of rising export prices of cashews in Mozambique in the early 1990s resulting from reduced export restrictions accrued to cashew farmers, owing to the significant market power of trading intermediaries.

It therefore appears possible that middleman markups can provide an explanation for the failure of trade liberalization to lower inequality in developing countries as predicted by the classical Stolper-Samuelson theorem. Goldberg and Pavcnik (2007) provide a comprehensive survey of the empirical evidence on this issue (see also Hanson and Harrison (1999) and Winters, McCulloch and McKay (2004)). Most of the studies reported use the ratio of earnings of those in white-collar or non-production occupations to those in blue-collar or production occupations as a measure of inequality. Trade liberalization has not resulted in a systematic reduction in this measure of inequality, with various studies often finding a tendency for inequality to rise. Moreover, this tends to happen frequently within industries or firms. Interpreting entrepreneurs or middlemen as white-collar occupations, and suppliers or workers as blue-collar occupations, our theory can be used to explore the channels by which trade liberalization or foreign direct investment 
can affect their relative earnings.

\subsection{Our Model}

We construct a two sector, two occupation, two country (North-South) general equilibrium model with endogenous reputational rents earned by entrepreneurs. It departs from most existing literature on trade in two ways. ${ }^{5}$ First, entrepreneurial rents arise as a result of scarcity of managerial ability, or of wealth (combined with capital market imperfections). Each firm is identified with a single entrepreneur; the free entry condition takes the form of equality of firm profits with the rents of the entrepreneur. Only entrepreneurs with the ability (or wealth) required to manage (or finance) firms above an endogenously determined threshold actually enter.

The minimum size thresholds for entry are entirely endogenous and not driven by any technological nonconvexity. They depend on the other distinguishing feature of our model: the need for firms to develop reputations for (unobservable) product quality. In contrast, most existing models of trade and product quality assume that the latter is observable by customers at the point of sale (e.g., Auer and Chaney (2009), Hallak and Sivadasan (2009), Sutton (2007)). ${ }^{6}$ Problems with unobservable quality have been prominent in recent scandals concerning quality of Chinese exports of farm products and toys. We view an essential role of trade intermediaries or entrepreneurs is to develop and maintain reputation for quality; the margins that accrue to them represent rents that provide them with the necessary incentives.

We model quality moral hazard problems similar to Biglaiser and Friedman (1994): entrepreneurs have an incentive to make short-term gains from skimping on quality, which customers will not be able to recognize at the point of sale, but only afterwards when they consume the good. Reputational considerations naturally create economies of scale: high-volume sellers have more at stake if their reputations are destroyed. This is the source of the minimum size threshold required for entry into the intermediary trade: we extend the Biglaiser-Friedman model to incorporate these factors.

\footnotetext{
${ }^{5}$ An exception is the model of Manasse and Turrini (2001), in which entrepreneurs earn rents owing to a scarcity of skills. Our model differs from theirs by incorporating unobserved product quality and related reputational phenomena.

${ }^{6}$ Bardhan and Kletzer (1984) present a model of choice of technology in a developing country between a local low-quality process and an imported high-quality process, but do not embed this in a open economy general equilibrium model.
} 
Given an underlying distribution of entrepreneurial ability or wealth in the population, agents sort into occupations (entrepreneurship and production workers, or traders and producers) and sectors. The two products differ in their requirements of labor vis-a-vis value-added activities provided by entrepreneurs, and in the intensity of the quality moral hazard problem. We refer to the inputs provided by the entrepreneur and workers as 'skilled' and 'unskilled' labor respectively. The South has a comparative advantage in the less skill intensive good (which we denote as the L-good, while the more skill intensive good is called the C-good).

The main assumption on the technology is that the L-good is subject to a greater moral hazard problem. This reflects greater difficulties in standardization and quality control. The C-good is more durable; it is produced in a more automated and regulated production process which is easier to inspect, and thus allows less scope for skimping on labor or other essential raw material requirements. ${ }^{7}$ This is consistent with recent concerns expressed over safety standards of Chinese exports of farm products and toys in recent years.

A simplifying assumption is that the nature of the moral hazard problem in each sector does not vary across countries. In Appendix A we explain how the results are modified when we alter assumptions concerning moral hazard, e.g., if the more skill-intensive good is subject to greater moral hazard. In this case, the conventional Stolper-Samuelson result always obtains with a Leontief fixed coefficient technology, provided both countries are subject to the same moral hazard in each sector. If the Southern country is subject to greater moral hazard, it tends to increase middlemen markup and lower wages. It also tends to lower comparative advantage of the South in the $L$ good, if this good is more prone to moral hazard. It is also possible for trade liberalization to raise inequality in both countries.

\footnotetext{
${ }^{7}$ An offsetting factor would be the greater technological complexity of these goods, combining a larger number of components in the production process. This may lead to high costs of ensuring high quality, as emphasized in the O-ring theory of Kremer (1993). We are assuming that greater difficulties of production inspection and provision of warranties in farm products or garments outweigh the costs of coordinating a large number of inputs in high-tech products.
} 


\subsection{Principal Results}

Equilibria in a closed economy are shown to be either of two types, depending on underlying parameters. In one, with a relatively low price of the Lgood, returns to entrepreneurial ability are equalized across the two sectors. This equilibrium is of the traditional "neoclassical" type, where incentive constraints do not restrict the movement of entrepreneurs across sectors. In the other with a relatively high price of the L-good, the returns to ability are higher in the L-sector sector. Entrepreneurs would thus strictly prefer to locate in this sector, but the incentive constraint binds, leading to a higher minimum ability threshold for entering this sector. Those with high enough ability enter the L-sector; others with intermediate ability do not meet the minimum threshold and so have no option but to enter the C-sector instead. ${ }^{8}$ Equilibria of this latter sort are "non-neoclassical" and exhibit restrictions on movement of entrepreneurs across sectors owing to the severity of moral hazard problems associated with entrepreneurship in the lucrative L-sector.

Our principal focus is on the distributive effects of trade liberalization. The relative abundance of unskilled labor in the South confers to it a comparative advantage in production of the L-good. Trade liberalization thus raises demand for the L-good in the South. If the economy was operating in the "non-neoclassical" type of equilibrium, the skill premium (interpreted as ratio of entrepreneurial rents to wages of workers) must rise within this sector. Since the incentive constraint associated with entrepreneurship is binding in this type of equilibrium, expanded production of the L-good requires entry thresholds to be lowered in this sector. This requires a rise in reputation rents earned by L-sector entrepreneurs relative to wages of production workers (since unskilled wages form the outside option of entrepreneurs, in the event that they lose their brand-name reputation).

Hence the gap between the export price and price received by suppliers (or wages earned by production workers) rises in the export sector: there is limited pass-through of the gains of export expansion to ultimate producers. Inequality defined by the relative earnings of white-collar and blue-collar occupations rises both within the export sector and within firms located in this sector. The extent to which this occurs depends on the extent to which there is additional entry into intermediation or entrepreneurship in the export sector. If the economy-wide distribution of managerial talent or

\footnotetext{
${ }^{8}$ Those who do not meet the lower threshold of the C-sector sector become unskilled workers.
} 
entrepreneurial wealth is thin at the existing entry threshold, there will be relatively little entry, the bargaining power of intermediaries will rise vis-avis producers, and pass-through of prices and output expansion in the export sector will be limited.

These results are consistent with empirical findings concerning the easing of export regulations or trade liberalization cited above. Our model provides detailed predictions concerning parameters that influence the trade effect on skill premia, which could potentially be empirically tested in future research. For instance, the model predicts opposite effects on intermediary margins and skill-premia in exporting and importing sectors, and predicts that these occur within firms or supplier-intermediary contractual relationships. Changes in markups are related to entry and exit of intermediaries or entrepreneurs, and are thus related to output effects of trade liberalization. Moreover, as we explain below, distributive effects of foreign direct investment or offshoring are predicted to be the opposite of those of trade liberalization.

Our model generates novel normative implications. Efficiency effects of trade liberalization include (apart from standard allocative benefits) effects on the gap between entrepreneurial rents in different sectors and wages of unskilled workers. Agents on the margin between sectors and occupations are subject to discrete increases in incomes as they are enabled to move to their preferred options by a relaxation of incentive constraints, if the economy is operating in the "non-neoclassical" region. These constraints depend on prices; hence the model is characterized by pervasive pecuniary externalities. In the "non-neoclassical" regime, thus, trade is associated with income effects in addition to the traditional allocative effects. If the moral hazard problem in the $C$-sector is negligible relative to that in the $L$-sector, the income effects expand the welfare gains from trade for the South country, and lower them for the North country. Starting from autarky, a small expansion of trade can thus be welfare reducing in the North. The underlying reason is that reputation rents in the L-sector exceed those in the C-sector, owing to the greater moral hazard problem in the former. These rent effects swamp the traditional allocative benefits associated with trade liberalization, since the latter are second-order starting from an autarky position.

The model shows trade liberalization causes a narrowing of North-South differentials of wages of workers, but does not yield full convergence in the absence of any trade barriers. This creates an incentive for Northern entrepreneurs to shift production operations to the South. The distributive implications of such offshoring tends to be the opposite of trade liberaliza- 
tion: e.g., it tends to reduce skill premia in the L-sector in the South, and (under additional assumptions) raise wages. Moreover, the distributional effects of full integration (free trade-cum-costless-offshoring) relative to autarky are in general the opposite of free trade alone.

Alternative theories of outsourcing and effects on inequality have been provided by Antras, Garicano and Rossi-Hansberg (2006), Feenstra and Hanson (1996) and Kremer and Maskin (2003). Of these, the most closely related to ours is Antras et.al, who develop a model in which agents of heterogenous abilities sort into hierarchical teams (which extends Kremer and Maskin's model in a variety of directions). Inequality rises in the South in their model owing to the matching of high ability agents in the South with worker teams from the North. Our theory differs by including two goods, which allows an analysis of effects of trade liberalization as well as offshoring. Rents arise owing to moral hazard and reputational effects, rather than matching of heterogenous agents. Their theory predicts that offshoring raises inequality in the South, whereas our model shows the effect tends to go the other way.

Section 2 introduces the model of the closed economy. Section 3 describes the equilibrium of the supply-side, where product prices are taken as given. Section 4 describes the economy-wide equilibrium, and comparative static properties. Section 5 then extends it to a two country context and studies effects of trade liberalization. Section 6 considers incentives and effects of offshoring. Section 7 concludes. Appendix A discusses extensions to the case of different assumptions concerning moral hazard in different sectors and countries, and effects of changing safety standards in any given country. Technical proofs are collected in Appendix B.

\section{Closed Economy Model}

\subsection{Endowment and Technology}

We normalize the size of the population to unity. Each agent is characterized by a level of entrepreneurial skill $a$, a nonnegative real variable. We provide alternative interpretations of 'skill' below. A fraction $1-\mu$ of agents have no skill at all: $a=0$ : we refer to them as unskilled. The remaining fraction $\mu$ are skilled; the distribution of skill is given by a $\operatorname{cdf} G(a)$ on $(0, \infty)$. We shall frequently use the notation $d(a) \equiv \int_{a}^{\infty} \tilde{a} d G(\tilde{a})$. The cdf $G$ will be assumed to have a density $g$ which is positive-valued. Then $d$ is a strictly decreasing 
and differentiable function.

There are two products $L$ and $C$ that are produced and consumed in the economy. We now describe the production technology. A product is produced and sold by an entrepreneur (or intermediary), upon hiring unskilled workers (or contracting with product suppliers). The level of production depends on the amount of unskilled labor hired, and the entrepreneur's skill. It also depends on the quality of the product, which can be either high or low.

We provide two different interpretations of entrepreneurial 'skill':

(a) Access to Capital: The good is produced by workers or suppliers upon applying their labor to raw materials that need to be purchased in advance. The entrepreneur purchases these raw materials and makes them available to the suppliers. Producing the high quality good requires more raw materials. $a$ represents the extent of working capital that the entrepreneur can finance upfront, which (owing to an imperfect capital market) is a function of the level of his personal wealth. $a$ units of raw materials with high quality can be purchased with $a$ units of working capital finance, while $z_{i} a$ unit of raw materials with low quality can be purchased by $a$ unit of wealth in a sector $i=L, C$ firm. $z_{i}>1$ is a parameter representing quantity-quality tradeoffs in production. A firm in sector $i$ associated with an entrepreneur or intermediary of skill $a$ then has a production function $X_{i}=A_{i} F_{i}\left(N_{i}, a\right)$ for the high-quality good, and $X_{i}=A_{i} F_{i}\left(N_{i}, z_{i} a\right)$ of the low-quality good, where $A_{i}$ is a TFP parameter, and $N_{i}$ workers are hired. Here the distribution over $a$ corresponds to the distribution of collateralizable wealth of potential entrepreneurs in the economy.

(b) Production Supervision: Workers hired by the entrepreneur need to be supervised, or the quality of the goods they produce need to be checked. The entrepreneur has a finite supervisory capacity $a$ which is equally divided between workers. If $N_{i}$ workers are hired, each of them are supervised to the extent $\frac{a}{N_{i}}$. The output produced by each worker depends on his effort, which is an increasing function $h\left(\frac{a}{N_{i}}\right)$ of the extent to which he is supervised, if the good produced is of high quality. If the good produced is of low quality, each worker can produce more for a given extent of supervision, so effective supervision per worker increases by a proportion $\left(z_{i}-1\right)$. Hence total output of the firm is $N_{i} h\left(\frac{a}{N_{i}}\right)$ if the good is high-quality, and $N_{i} h\left(\frac{z_{i} a}{N_{i}}\right)$ if it is of low quality. 
Both these possibilities are captured by a production function for a firm in sector $i$ given by $X_{i}=A_{i} F_{i}\left(N_{i}, a\right)$ for the high quality good, and an output which is $z_{i}$ times this if it is the low quality good. We shall assume that $F_{i}$ is a CRS, smooth and concave production function, and $A_{i}$ is a TFP parameter.

An underlying assumption is that each firm is managed by exactly one entrepreneur, so the size of the firm is limited by the skill of its manager. In practice, of course, firms may employ more than one manager in order to grow, but problems of managerial moral hazard and coordination across managers eventually limit the size of firms (as emphasized by a large literature on 'organizational diseconomies of scale', e.g., Williamson (1967), Calvo and Wellisz (1978), Keren and Levhari (1983), Qian (1994) or van Zandt and Radner (2001)). In order to explore the industry or general equilibrium implications of limits to the size of firms created by such problems, we adopt the simplifying assumption that a firm is managed by a single entrepreneur, similar to Lucas (1978).

Note that neither unskilled or skilled labor is specific to either sector. Skilled labor is equated with entrepreneurship. Given the assumption that a firm can have only one manager, there will be no market for entrepreneurs: every entrepreneur works for herself, i.e., managing her own firm. Entrepreneurial rents will correspond to imputed prices of 'skill' which will be equalized across all agents, and which will clear the market for skill. Entrepreneurial rents in any sector will be linear in the extent of skill of the entrepreneur concerned. This allows a simple measure of the returns to skill to entrepreneurs or white-collar workers relative to workers or suppliers within any sector.

Consider the cost-minimizing factor combinations in each sector, when skill is imputed a cost $\gamma$ relative to unskilled labor: $\left(\theta_{N}^{C}(\gamma), \theta_{a}^{C}(\gamma)\right)$ and $\left(\theta_{N}^{L}(\gamma), \theta_{a}^{L}(\gamma)\right)$ are defined as

$$
\left(\theta_{N}^{C}(\gamma), \theta_{a}^{C}(\gamma)\right) \equiv \arg \min \left\{\theta_{N}^{C}+\gamma \theta_{a}^{C} \mid F_{C}\left(\theta_{N}^{C}, \theta_{a}^{C}\right)=1\right\}
$$

and

$$
\left(\theta_{N}^{L}(\gamma), \theta_{a}^{L}(\gamma)\right) \equiv \arg \min \left\{\theta_{N}^{L}+\gamma_{C} \theta_{a}^{L} \mid F_{L}\left(\theta_{N}^{L}, \theta_{a}^{L}\right)=1\right\}
$$

The following assumption states that good $L$ is more labor intensive than good $C$ : for any common ratio of factor costs, production of $L$ uses a higher ratio of unskilled labor to skilled labor in the cost-minimizing factor choice. One can think of $L$ as corresponding to agricultural products or low-end manufactured goods, while $C$ corresponds to high-tech manufactured goods or services. 
Assumption 1 For any $\gamma>0$,

$$
\frac{\theta_{N}^{L}(\gamma)}{\theta_{a}^{L}(\gamma)}>\frac{\theta_{N}^{C}(\gamma)}{\theta_{a}^{C}(\gamma)}
$$

\subsection{Entrepreneur's Profit Maximization and Incentive Constraint}

\section{Profit maximization}

Consider an entrepreneur in sector $L$, facing a product price of $p_{L}$ (with the $C$ good acting as numeraire, so $p_{C} \equiv 1$ ). Suppose the wage rate for unskilled labor is $w$. If this entrepreneur were to decide to produce the high quality version of product $L$, she would solve the following problem:

$$
\max _{N_{L}} p_{L} A_{L} F_{L}\left(N_{L}, a\right)-w N_{L}
$$

The optimal employment of unskilled labor $N_{L}^{*}$ is a function of $p_{L} / w$, characterized by the first-order condition

$$
\left(p_{L} / w\right) A_{L} \partial F_{L}\left(N_{L}^{*}, a\right) / \partial N_{L}=1 .
$$

Let $\Pi_{L}^{*}\left(p_{L}, w ; a\right)$ denote the resulting level of profit earned by the entrepreneur. Define

$$
\gamma_{L} \equiv \frac{\Pi_{L}^{*}}{w a}
$$

which can be interpreted as a skill premium in the $L$ sector: the per-skill-unit return to entrepreneurs relative to the unskilled wage. This skill premium will play a key role in the analysis below.

Recall the definition of $\left(\theta_{N}^{L}(\gamma), \theta_{a}^{L}(\gamma)\right)$ as cost-minimizing factor combination in sector $L$ corresponding to $A_{L}$ unit of production and $\gamma$ the relative cost of skill. Given the CRS property of the production function, it follows 
that $^{9}$

$$
\left(\theta_{N}^{L}\left(\gamma_{L}\right), \theta_{a}^{L}\left(\gamma_{L}\right)\right)=\left(\frac{N_{L}^{*}}{F_{L}\left(N_{L}^{*}, a\right)}, \frac{a}{F_{L}\left(N_{L}^{*}, a\right)}\right)
$$

Using the definition (3) of $\gamma_{L}$, we can express the ratio of product price to wage as

$$
\begin{aligned}
\frac{p_{L}}{w} & =\frac{N_{L}^{*}+a \gamma_{L}}{A_{L} F_{L}} \\
& =\frac{1}{A_{L}}\left[\frac{N_{L}^{*}}{F_{L}}+\gamma_{L} \frac{a}{F_{L}}\right] \\
& =\frac{1}{A_{L}}\left[\theta_{N}^{L}\left(\gamma_{L}\right)+\gamma_{L} \theta_{a}^{L}\left(\gamma_{L}\right)\right]
\end{aligned}
$$

This equation can be interpreted as expressing equality of prices with unit costs, using $\gamma_{L}$ as the imputed price of skill in sector $L$. It expresses a monotone increasing relation between the ratio $\frac{p_{L}}{w}$ and the skill premium in sector $L$.

A similar analysis for sector $C$ yields an analogous price-cost relation:

$$
\frac{1}{w}=\frac{\theta_{N}^{C}\left(\gamma_{C}\right)+\gamma_{C} \theta_{a}^{C}\left(\gamma_{C}\right)}{A_{C}}
$$

where $\gamma_{C}$ denotes the imputed price of skill in sector $C$. This equation expresses a monotone decreasing relation between the wage rate $w$ and the skill premium in sector $C$.

Dividing (5) by (6), we obtain the following equation which plays an important role in the equilibrium analysis in later sections:

$$
p_{L}=\frac{A_{C}}{A_{L}} \frac{\theta_{N}^{L}\left(\gamma_{L}\right)+\gamma_{L} \theta_{a}^{L}\left(\gamma_{L}\right)}{\theta_{N}^{C}\left(\gamma_{C}\right)+\gamma_{C} \theta_{a}^{C}\left(\gamma_{C}\right)} .
$$

${ }^{9}$ Euler's Theorem implies that $F_{L}\left(N_{L}^{*}, a\right)=\frac{\partial F_{L}}{\partial N_{L}} N_{L}^{*}+\frac{\partial F_{L}}{\partial a} a$. Hence

$$
\begin{aligned}
\gamma_{L} & =\frac{p_{L}}{w a} A_{L}\left[\frac{\partial F_{L}}{\partial N_{L}} N_{L}^{*}+\frac{\partial F_{L}}{\partial a} a\right]-\frac{N_{L}^{*}}{a} \\
& =\frac{p_{L}}{w} A_{L} \frac{\partial F_{L}}{\partial a} \\
& =\frac{\frac{\partial F_{L}\left(N_{L}^{*}, a\right)}{\partial a}}{\frac{\partial F_{L}\left(N_{L}^{*}, a\right)}{\partial N_{L}}}
\end{aligned}
$$

upon using the first order condition (2). It follows from this that $\left(N_{L}^{*}, a\right)$ is a costminimizing factor combination, if we use $\gamma_{L}$ as the (imputed) factor cost of a unit of entrepreneurial skill relative to unskilled labor. 
It can be interpreted as equality of relative prices and unit costs of the two products. Note that the right-hand-side is increasing in the skill premium in sector $L$, and decreasing in the skill premium in sector $C$. Hence (7) expresses a relation between the skill premia in the two sectors, and the price $p_{L}$ of product $L$ relative to $C$. This can be expressed as follows:

$$
\gamma_{L}=\lambda\left(\gamma_{C} ; p_{L}, \frac{A_{C}}{A_{L}}\right)
$$

For any given product price $p_{L}$ and set of TFP parameters, it expresses a monotone increasing relation between the skill premia in the two sectors. And for any given $\gamma_{C}$ and TFP parameters, it expresses a monotone increasing relation between $p_{L}$ and $\gamma_{L}$.

Various properties of this relationship between skill premia in the two sectors will be used subsequently. For now we note one property which plays an important role in establishing uniqueness of equilibrium.

Lemma $1 \frac{d \gamma_{L}}{d \gamma_{C}} \equiv \lambda_{1}\left(\gamma_{C} ; p_{L}, \frac{A_{C}}{A_{L}}\right)>1$ whenever $\gamma_{L} \geq \gamma_{C}$.

Proof of Lemma 1: Implicitly differentiating (7) we obtain

$$
\frac{d \gamma_{L}}{d \gamma_{C}}=p_{L} \frac{A_{L}}{A_{C}} \frac{\theta_{a}^{C}}{\theta_{a}^{L}}=\frac{\theta_{N}^{L}+\gamma_{L} \theta_{a}^{L}}{\theta_{N}^{C}+\gamma_{C} \theta_{a}^{C}} \frac{\theta_{a}^{C}}{\theta_{a}^{L}}=\frac{\gamma_{L}+\frac{\theta_{N}^{L}}{\theta_{a}^{L}}}{\gamma_{C}+\frac{\theta_{N}^{C}}{\theta_{a}^{C}}}>1
$$

with the second equality using (7), and the last inequality following from Assumption $1, \gamma_{L} \geq \gamma_{C}$ and the fact that $\frac{\theta_{N}^{L}}{\theta_{a}^{L}}$ is non-decreasing in $\gamma_{L}$.

This Lemma states that if the skill premium in sector $L$ is higher than in sector $C$ to start with, a further increase in the sector $C$ premium (with given $\left.p_{L}, A_{L}, A_{C}\right)$ must be accompanied by a larger increase in the premium in sector $L$. Assumption 1 plays an important role here. Since sector $L$ is less skill-intensive, an equal increase in the skill premium in the two sectors will cause unit cost in the $L$ sector to increase by less than in the $C$ sector. Hence the premium must rise by more in the $L$ sector to ensure that the ratio of unit costs remains the same.

\section{Incentive Constraint of Entrepreneurs}


Customers do not observe the quality of the product at the point of sale. We assume they value only the high quality version of the product, and obtain no utility from the low quality version. Entrepreneurs will be tempted to produce the low quality version which enables them to produce and sell more to unsuspecting customers. The short-run benefits of such opportunism can be held in check by possible loss of the seller's reputation. With probability $\eta_{i}$, an entrepreneur selling a low-quality item in sector $i$ will be publicly exposed (say by a product inspection agency or by investigating journalists). In this event the entrepreneur's brand-name reputation is destroyed, and the agent in question is forever barred from entrepreneurship. In equilibrium, customers will purchase only from entrepreneurs for whom the threatened loss of reputation is sufficient to deter short-term opportunism. Hence in order for an entrepreneur with skill $a$ to be able to operate in sector $i$, the following incentive constraint must be satisfied:

$$
\frac{\gamma_{i} w a}{1-\delta} \geq \gamma_{i} w z_{i} a+\delta\left[\eta_{i} \frac{w}{1-\delta}+\left(1-\eta_{i}\right) \frac{\gamma_{i} w a}{1-\delta}\right]
$$

where $\delta \in(0,1)$ denotes a common discount factor for all agents. The lefthand-side of (9) is the present value of producing and selling the high quality version of good $i$ for ever. The first term on the right-hand-side, $\gamma_{i} w z_{i} a$ represents the short-term profit that can be attained by the entrepreneur upon deviating to low quality. ${ }^{10}$ With probability $\eta_{i}$, this deviation results in the entrepreneur losing her reputation for ever, in which case the agent is forced to work as an unskilled agent thereafter. With the remaining probability the entrepreneur's reputation remains intact.

The incentive constraint can be equivalently expressed as

$$
a \geq m_{i} / \gamma_{i}
$$

where

$$
m_{i} \equiv \frac{\delta \eta_{i}}{\delta \eta_{i}+(1-\delta)\left(1-z_{i}\right)}>1
$$

is a parameter representing the severity of the moral hazard problem in sector $i$. Equation (10) represents a fundamental reputational economy of scale, which also translates into a sector-specific entry barrier in terms of entrepreneurial skill required. Intuitively, higher skilled entrepreneurs produce

\footnotetext{
${ }^{10}$ Recall that a deviation to low quality is equivalent to an increase in the entrepreneur's effective skill from $a$ to $z_{i} a$.
} 
and earn profits at a higher scale (conditional on being able to operate as an entrepreneur), while the consequences of losing one's reputation is independent of the level of skill. The stake involved in losing reputation is thus proportional to the entrepreneurs skill, which has to be large enough for the agent to be a credible seller of a high-quality good. We assume customers can infer quality from observing the size of the corresponding firm and existing prices, by checking whether the incentive constraint is satisfied.

Note that the skill threshold for entry into a particular sector is decreasing in the skill premium in that sector. The reason is simple: a higher skill premium means entrepreneurs have more to lose from losing their reputations. The skill premia depends in turn on prices and wages; hence so do the incentive constraints. This will represent the key pecuniary externality in the model.

Note also that $m_{i}>1$ implies that entrepreneurs with skills above the required threshold for sector $i$ will strictly prefer to be entrepreneurs in sector $i$ rather than work as an unskilled agent. The per period profit from the former option is $\gamma_{i} w a \geq w m_{i}>w$ if (10) is satisfied.

We now introduce the second major assumption of the model, which states that product $L$ is subject to a more severe moral hazard problem compared with product $C$.

\section{Assumption $2 m_{L}>m_{C}$}

This seems descriptively accurate - agricultural products or low-end manufacturing products appear to be more prone to quality problems than high-tech products. This may owe to differences in effective inspection rates, or to greater scope for manipulating relatively less-automated production processes. It will also turn out as a consequence that the $L$ sector will be characterized by higher margins and a more concentrated structure of trade intermediaries. Appendix A will explain the consequences of reversing this assumption.

\section{Industry Equilibrium}

In this section we take the product prices as given, and derive the resulting equilibrium of the supply-side of the economy. 


\subsection{Occupational Choice and Factor-Market Clearing}

First we take the skill premia in different sectors as given, and describe occupational choices of agents in the economy. This determines the demand and supply of unskilled labor. The requirement that the factor market clears serves to determine a relationship between the skill premia in the two sectors. Eventually the supply-side equilibrium will be determined by the factor market clearing condition, and the relation (7) between prices and skill premia in the two sectors.

Occupational choices will depend on skill premia, as these determine both incentive constraints defining entry into the two production sectors, and their relative profitability. There are four cases to consider.

Case 1: $\gamma_{L} \geq \gamma_{C} \frac{m_{L}}{m_{C}}$

Since by Assumption 2, $\frac{m_{L}}{m_{C}}>1$, it follows that in this case $\gamma_{L}>\gamma_{C}$ also holds. This implies that entrepreneurship in sector $L$ is more profitable than in sector $C$. The entry threshold for this sector is also lower, as $\frac{m_{L}}{\gamma_{L}}<\frac{m_{C}}{\gamma_{C}}$. Hence all those with skill above $\frac{m_{L}}{\gamma_{L}}$ will enter the $L$ sector, and those below will become unskilled workers. Clearing of the labor market requires

$$
\mu\left[\frac{\theta_{N}^{L}\left(\gamma_{L}\right)}{\theta_{a}^{L}\left(\gamma_{L}\right)}\right] d\left(a_{L}\right)=\mu G\left(a_{L}\right)+(1-\mu) .
$$

The production levels will be $X_{C}=0, X_{L}=\mu A_{L} d\left(a_{L}\right) / \theta_{a}^{L}\left(\gamma_{L}\right)$.

Case 2: $\gamma_{C}<\gamma_{L}<\gamma_{C} \frac{m_{L}}{m_{C}}$

Here $\gamma_{L}>\gamma_{C}$ implies that the $L$ sector is more profitable. On the other hand, the entry threshold is higher in the $L$ sector: $a_{L}=m_{L} / \gamma_{L}>m_{C} / \gamma_{C}=a_{C}$. So agents with $a \geq a_{L}$ will choose to become $L$-sector entrepreneurs, while agents with $a \in\left[a_{C}, a_{L}\right)$ are unable to enter the $L$ sector and so have to be content with becoming $C$-sector entrepreneurs. And agents with $a<a_{C}$ become workers.

The labor market clears if

$$
\mu\left[\frac{\theta_{N}^{L}\left(\gamma_{L}\right)}{\theta_{a}^{L}\left(\gamma_{L}\right)}\right] d\left(\frac{m_{L}}{\gamma_{L}}\right)+\mu\left[\frac{\theta_{N}^{C}\left(\gamma_{C}\right)}{\theta_{a}^{C}\left(\gamma_{C}\right)}\right]\left[d\left(\frac{m_{C}}{\gamma_{C}}\right)-d\left(\frac{m_{L}}{\gamma_{L}}\right)\right]=\mu G\left(\frac{m_{C}}{\gamma_{C}}\right)+(1-\mu) .
$$

This provides a condition that relates the skill premia in the two sectors. It is easily checked that this relationship is downward-sloping, because an 
increase in the skill premium in either sector tightens the labor market condition. To see this, note that a rise in $\gamma_{C}$ lowers the entry threshold into the $C$ sector, and raises the demand for unskilled workers for any given $C$ sector entrepreneur. And on the other hand a rise in the $L$ sector skill premium causes the skill threshold for the $L$ sector to fall, motivating some entrepreneurs to switch from the $C$ to the $L$ sector. By Assumption 1, and the fact that $\gamma_{L}>\gamma_{C}, L$ sector entrepreneurs demand more unskilled workers than the $C$ sector entrepreneurs. So the switch of entrepreneurs between the two sectors tightens the labor market. This is accentuated by the rise in demand for workers by incumbent $L$ sector entrepreneurs.

In this case, production levels are:

$$
\begin{gathered}
X_{C}=\mu A_{C}\left[d\left(a_{C}\right)-d\left(a_{L}\right)\right] / \theta_{a}^{C}\left(\gamma_{C}\right) \\
X_{L}=\mu A_{L} d\left(a_{L}\right) / \theta_{a}^{L}\left(\gamma_{L}\right)
\end{gathered}
$$

Case 3: $\gamma_{C}=\gamma_{L}$

$\gamma_{L}=\gamma_{C}=\gamma$, say, implies that entrepreneurs are indifferent between the two sectors. The $L$ sector is harder to enter, as $a_{L}=m_{L} / \gamma>m_{C} / \gamma=a_{C}$. Hence agents with $a \in\left[a_{C}, a_{L}\right)$ have no option but to enter sector $C$, while those with $a \geq a_{L}$ can enter either of the two sectors. The equilibrium in this case will involve a fraction of those with $a \geq a_{L}$ who will go to sector $L$, the remaining going to sector $C$. This fraction must be such as to permit the factor market to clear. We show now that this in turn translates into an upper and lower bound for the common skill premium $\gamma$.

Denoting the production levels by $X_{L}, X_{C}$ respectively, the factor market clearing conditions are

$$
\begin{gathered}
{\left[\theta_{N}^{L}(\gamma) / A_{L}\right] X_{L}+\left[\theta_{N}^{C}(\gamma) / A_{C}\right] X_{C}=\mu G\left(a_{C}\right)+(1-\mu)} \\
{\left[\theta_{a}^{L}(\gamma) / A_{L}\right] X_{L}+\left[\theta_{a}^{C}(\gamma) / A_{C}\right] X_{C}=\mu d\left(a_{C}\right)}
\end{gathered}
$$

These equations are equivalent to

$$
\begin{gathered}
X_{L}=A_{L} \frac{\theta_{a}^{C}(\gamma)\left[\mu G\left(a_{C}\right)+(1-\mu)\right]-\theta_{N}^{C}(\gamma) \mu d\left(a_{C}\right)}{\theta_{N}^{L}(\gamma) \theta_{a}^{C}(\gamma)-\theta_{N}^{C}(\gamma) \theta_{a}^{L}(\gamma)} \\
X_{C}=A_{C} \frac{-\theta_{a}^{L}(\gamma)\left[\mu G\left(a_{C}\right)+(1-\mu)\right]+\theta_{N}^{L}(\gamma) \mu d\left(a_{C}\right)}{\theta_{N}^{L}(\gamma) \theta_{a}^{C}(\gamma)-\theta_{N}^{C}(\gamma) \theta_{a}^{L}(\gamma)} .
\end{gathered}
$$


However since only agents with $a \geq a_{L}$ have the option to become $L$-sector entrepreneurs,

$$
X_{L} \leq \mu A_{L} d\left(a_{L}\right) / \theta_{a}^{L}(\gamma)
$$

which implies

$$
\mu\left[\frac{\theta_{N}^{L}(\gamma)}{\theta_{a}^{L}(\gamma)}\right] d\left(\frac{m_{L}}{\gamma}\right)+\mu\left[\frac{\theta_{N}^{C}(\gamma)}{\theta_{a}^{C}(\gamma)}\right]\left[d\left(\frac{m_{C}}{\gamma}\right)-d\left(\frac{m_{L}}{a_{L}}\right)\right] \geq \mu G\left(\frac{m_{C}}{\gamma}\right)+(1-\mu) .
$$

On the other hand, $X_{L} \geq 0$ implies

$$
\mu\left[\frac{\theta_{N}^{C}(\gamma)}{\theta_{a}^{C}(\gamma)}\right] d\left(\frac{m_{C}}{\gamma}\right) \leq \mu G\left(\frac{m_{C}}{\gamma}\right)+(1-\mu) .
$$

Inequalities $(13,14)$ provide lower and upper bounds on the common premium rate $\gamma$. Note that (13) is the inequality version of the factor market clearing condition (12) in Case 2. Hence the lower bound in Case 3 exactly equals the limiting premia in Case 2 as $\gamma_{L}$ and $\gamma_{C}$ approach each other. This will be shown in the figure below.

Case 4: $\gamma_{C}>\gamma_{L}$

$\gamma_{C}>\gamma_{L}$ implies that sector $C$ is more profitable. Also the entry threshold in sector $C$ is lower. In this case no entrepreneur enters sector $L$. Those with skill $a \geq a_{C}$ enter sector $C$, the rest become workers. The labor market condition is

$$
\mu\left[\frac{\theta_{N}^{C}\left(\gamma_{C}\right)}{\theta_{a}^{C}\left(\gamma_{C}\right)}\right] d\left(a_{C}\right)=\mu G\left(a_{C}\right)+(1-\mu) .
$$

The production levels are

$$
\begin{gathered}
X_{L}=0 \\
X_{C}=\mu A_{C} d\left(a_{C}\right) / \theta_{a}^{C}\left(\gamma_{C}\right) .
\end{gathered}
$$

The relationship between skill premia in the two sectors that ensure the labor market clears is shown in Figure 1 below. The thresholds depicted $\gamma_{C}^{1}$, $\gamma_{C}^{2}$ and $\gamma_{C}^{3}$ are defined by the solutions to the following equations.

$$
\begin{gathered}
\mu\left[\frac{\theta_{N}^{L}\left(\frac{m_{L}}{m_{C}} \gamma_{C}^{1}\right)}{\theta_{a}^{L}\left(\frac{m_{L}}{m_{C}} \gamma_{C}^{1}\right)}\right] d\left(m_{C} / \gamma_{C}^{1}\right)=\mu G\left(m_{C} / \gamma_{C}^{1}\right)+(1-\mu) \\
\mu\left[\frac{\theta_{N}^{L}\left(\gamma_{C}^{2}\right)}{\theta_{a}^{L}\left(\gamma_{C}^{2}\right)}\right] d\left(m_{L} / \gamma_{C}^{2}\right)+\mu\left[\frac{\theta_{N}^{C}\left(\gamma_{C}^{2}\right)}{\theta_{a}^{C}\left(\gamma_{C}^{2}\right)}\right]\left[d\left(m_{C} / \gamma_{C}^{2}\right)-d\left(m_{L} / \gamma_{C}^{2}\right)\right]=\mu G\left(m_{C} / \gamma_{C}^{2}\right)+(1-\mu) .
\end{gathered}
$$




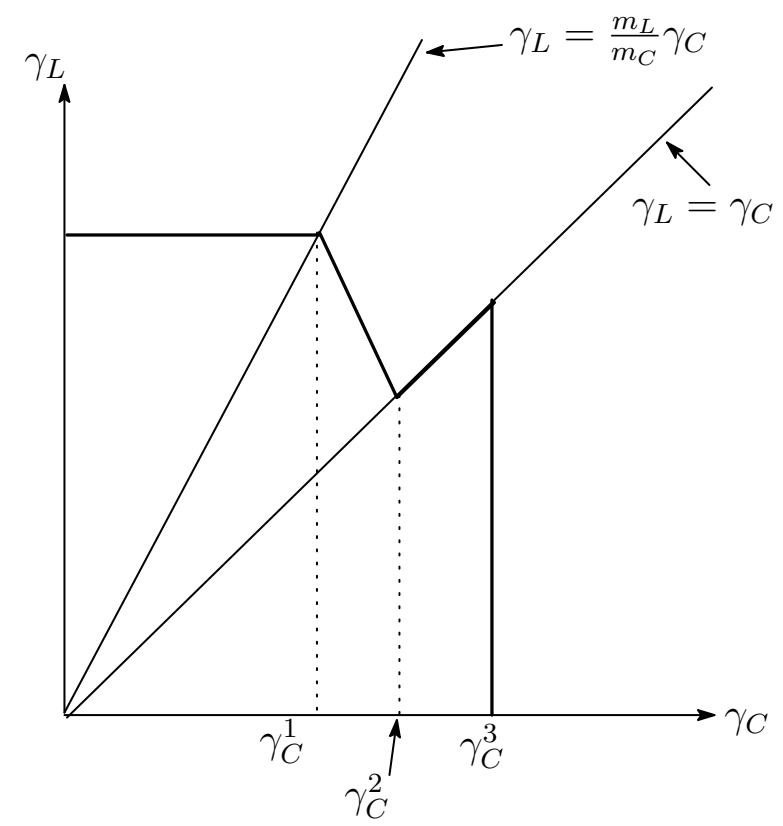

Figure 1: Relation Between Skill Premia for Factor Market Clearing

$$
\mu\left[\frac{\theta_{N}^{C}\left(\gamma_{C}^{3}\right)}{\theta_{a}^{C}\left(\gamma_{C}^{3}\right)}\right] d\left(m_{C} / \gamma_{C}^{3}\right)=\mu G\left(m_{C} / \gamma_{C}^{3}\right)+(1-\mu)
$$

For future reference, we shall denote this relationship by the equation

$$
\gamma_{L}=\psi\left(\gamma_{C}\right)
$$

Note that this function depends on parameters $\mu, m_{L}, m_{C}$ but is independent of $p_{L}$ or TFP parameters $A_{L}, A_{C}$. Note also that this function is well defined for $\gamma_{C}<\gamma_{C}^{3}$, and is not a monotone relationship: it is decreasing below $\gamma_{C}^{2}$ but increasing thereafter. The downward-sloping part corresponding to Case 2 is the 'non-classical' region where skill premia are not equalized across sectors. The upward-sloping part corresponding to Case 3 coincides with the line of equality, so this is the 'classical' region where skill premia are equalized. Note that the greater the relative severity $\frac{m_{L}}{m_{C}}$ of the moral hazard problem in the $L$-sector, the greater the range occupied by the non-classical region.

\subsection{Supply-Side Equilibrium}

We are now in a position to characterize the supply-side equilibrium, by putting together the condition that the labor market clears (which incorpo- 
rates reputation effects, occupational and sectoral choices by entrepreneurs), with the relation between prices and costs representing profit maximization by active entrepreneurs in each sector. The former is represented by the relation between skill premia that clears the factor markets, shown in the previous section. The latter is represented by the upward-sloping relation (7) between premia in the two sector for any given product price $p_{L}$. Geometrically it is represented by the intersection of the corresponding relations between the two skill premia. This is shown in Figure 2 for different values of $p_{L}$.

Proposition 1 For given $p_{L}>0$, as well as other parameters $\mu, A_{L}, A_{C}, z_{L}, z_{C}$, there is a unique supply-side equilibrium determining skill premia and outputs of the two sectors, as well as the wage rate.

We sketch the proof informally. For $i=1,2,3$, define threshold prices $p_{L}^{i}$ corresponding to threshold $C$-sector skill premia defined previously (which mark the transition between Cases 1,2, 3 and 4):

$$
\begin{gathered}
p_{L}^{1}=\left(A_{L} / A_{C}\right) \frac{\theta_{N}^{L}\left(\frac{m_{L}}{m_{C}} \gamma_{C}^{1}\right)+\frac{m_{L}}{m_{C}} \gamma_{C}^{1} \theta_{a}^{L}\left(\frac{m_{L}}{m_{C}} \gamma_{C}^{1}\right)}{\theta_{N}^{C}\left(\gamma_{C}^{1}\right)+\gamma_{C}^{1} \theta_{a}^{C}\left(\gamma_{C}^{1}\right)} \\
p_{L}^{2}=\left(A_{L} / A_{C}\right) \frac{\theta_{N}^{L}\left(\gamma_{C}^{2}\right)+\gamma_{C}^{2} \theta_{a}^{L}\left(\gamma_{C}^{2}\right)}{\theta_{N}^{C}\left(\gamma_{C}^{2}\right)+\gamma_{C}^{2} \theta_{a}^{C}\left(\gamma_{C}^{2}\right)} \\
p_{L}^{3}=\left(A_{L} / A_{C}\right) \frac{\theta_{N}^{L}\left(\gamma_{C}^{3}\right)+\gamma_{C}^{3} \theta_{a}^{L}\left(\gamma_{C}^{3}\right)}{\theta_{N}^{C}\left(\gamma_{C}^{3}\right)+\gamma_{C}^{3} \theta_{a}^{C}\left(\gamma_{C}^{3}\right)}
\end{gathered}
$$

Now consider the following price ranges.

Case 1: $p_{L} \geq p_{L}^{1}$

In this case, there is an equilibrium with $\gamma_{C} \leq \gamma_{C}^{1}$, with complete specialization in product $L$, and production levels $X_{L}=\mu d\left(\frac{m_{L}}{\gamma_{L}}\right) / \theta_{a}^{L}\left(\gamma_{L}\right), X_{C}=0$. Since the price-cost relation (7) between skill premia in the two sectors is upward-sloping, it is evident there cannot be any other equilibrium. In the interior of this range, the equilibrium outputs are locally independent of $p_{L}$.

Case 2: $p_{L}^{1}>p_{L} \geq p_{L}^{2}$ 


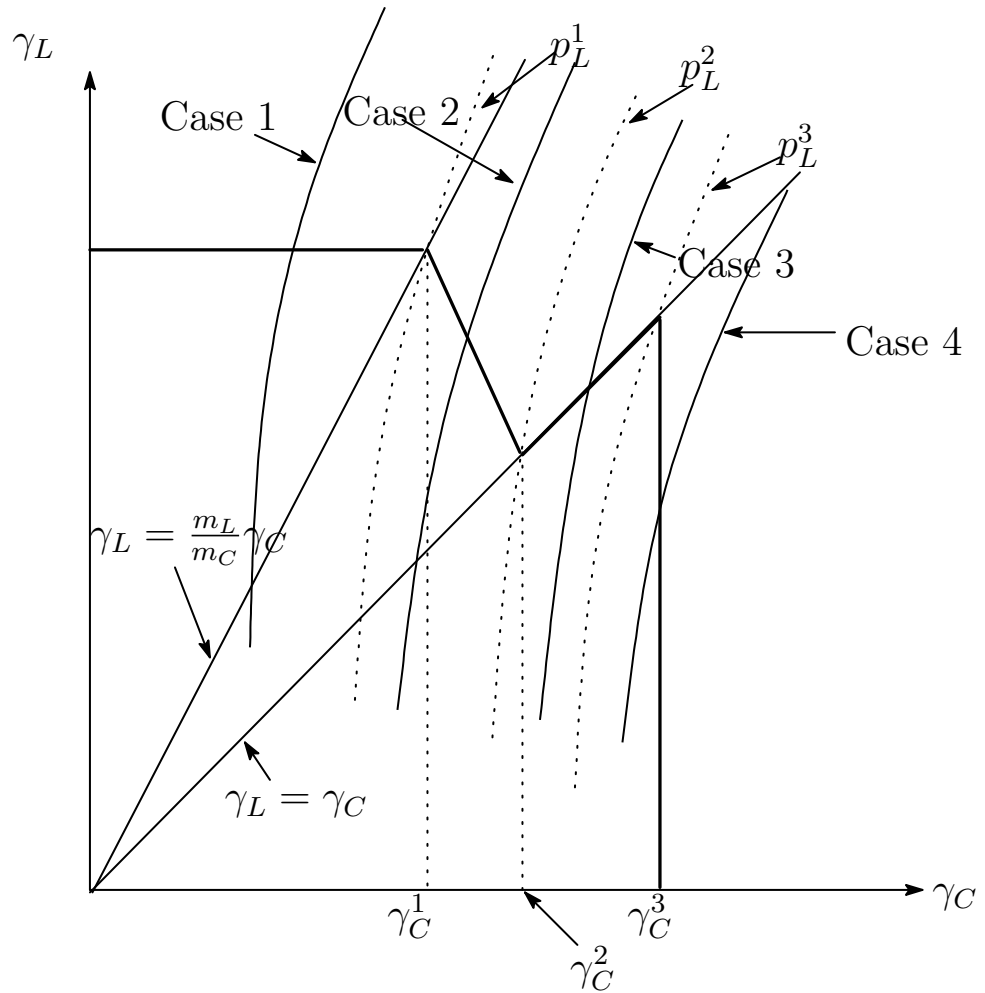

Figure 2: Supply-Side Equilibrium 
Here there is an equilibrium corresponding to the downward sloping stretch in the relation between $\gamma_{C}, \gamma_{L}$ expressing labor market clearing. This follows from the fact that at $p_{L}^{1}$ there is an equilibrium corresponding to $\gamma_{C}^{1}$, and at $p_{L}^{2}$ there is an equilibrium corresponding to $\gamma_{C}^{2}$. Moreover in this case there cannot be any other equilibrium owing to Lemma $1 .^{11}$

In the interior of this range of prices, increasing $p_{L}$ results in an increase in $X_{L}$ and $\gamma_{L}$, and a decrease in $X_{C}$ and $\gamma_{C}$.

Case 3: $p_{L}^{2}>p_{L} \geq p_{L}^{3}$

Now there will be an equilibrium in which skill premia are equalized across the two sectors. The same argument as in Case 2 ensures the equilibrium is unique. ${ }^{12}$ The equilibrium skill premium in this case $\gamma_{L}=\gamma_{C}=\gamma^{*}$ is determined by the condition

$$
p_{L}=\left(\frac{A_{C}}{A_{L}}\right) \frac{\theta_{N}^{L}\left(\gamma^{*}\right)+\gamma^{*} \theta_{a}^{L}\left(\gamma^{*}\right)}{\theta_{N}^{C}\left(\gamma^{*}\right)+\gamma^{*} \theta_{a}^{C}\left(\gamma^{*}\right)} .
$$

It is evident that an increase in $p_{L}$ will increase $X_{L}$, reduce $X_{C}$ and the common skill premium $\gamma^{*}$. The latter results as the shift in production towards the $L$ sector raises the demand for labor, inducing a rise in the wage rate.

Case 4: $p_{L}<p_{L}^{3}$

In this case, there is an unique equilibrium with perfect specialization in sector $C$, with production level

$$
X_{C}=\mu A_{C} d\left(a_{C}\right) / \theta_{a}^{C}\left(\gamma_{C}\right) .
$$

An increase in $p_{L}$ in this region will raise $\gamma_{L}$, while leaving $X_{C}, \gamma_{C}$ unchanged.

\subsection{Comparative Static Properties of the Supply-Side Equilibrium}

The distributional effects of changes in parameters can now be deduced.

\footnotetext{
${ }^{11}$ If there were another equilibrium, it would have to lie in the range $\gamma_{C}>\gamma_{C}^{2}$. But this would require the slope of the skill premium relationship expressing (7) to have a slope smaller than one somewhere above the 45 degree line, which is ruled out by Lemma 1 .

${ }^{12}$ Note in particular that Lemma 1 ensures that the slope of the relation between skill premia expressing (7) strictly exceeds unity even on the 45 degree line. Hence a tangency of this relation with the 45 degree line is ruled out.
} 


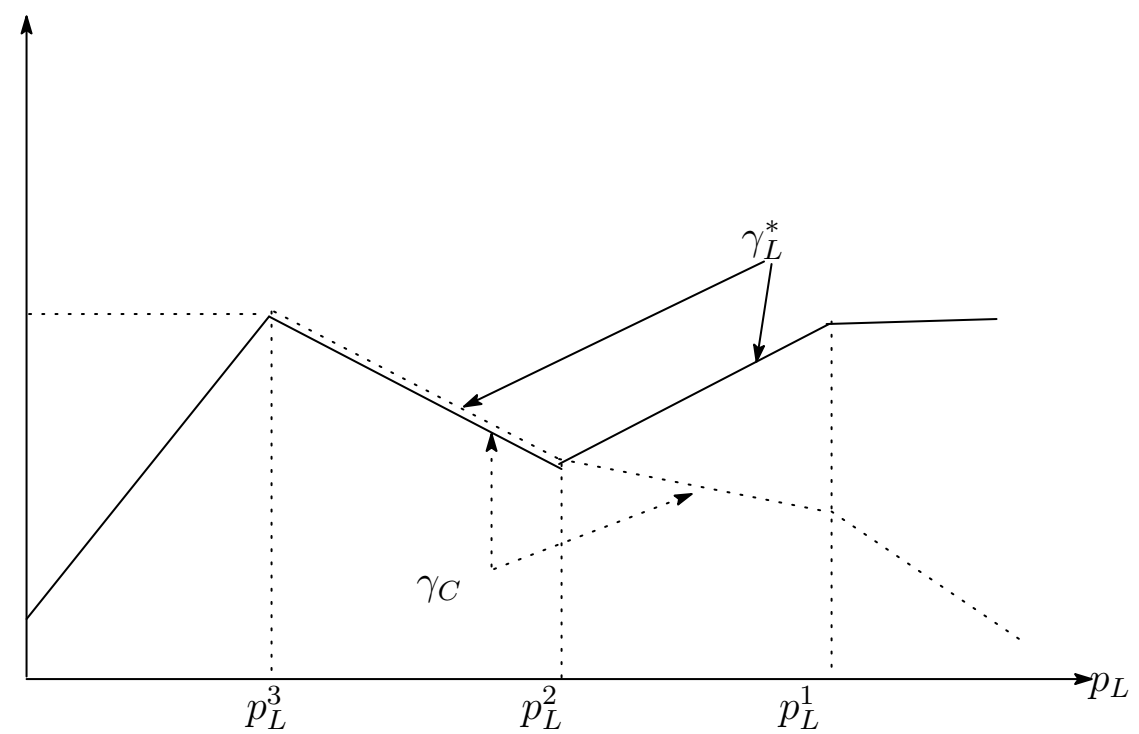

Figure 3: Effect of Changes in $p_{L}$ on Skill-Premia

\subsubsection{Rise in $p_{L}$}

Recall from the price-cost relations $(5,6)$ that the equilibrium wage rate $w$ moves inversely with the skill premium in the $C$ sector, and $\frac{p_{L}}{w}$ moves in the same direction as the skill premium in the $L$ sector. And from the discussion above, we can derive the effect of changing $p_{L}$ on skill premia in the two sectors. This relation is depicted in Figure 3.

Focusing on the region $p_{L}^{1}>p_{L}>p_{L}^{2}$ which corresponds to Case 2 above, a rise in $p_{L}$ raises the skill premium in sector $L$ and lowers it in sector $C$. This implies that $w$ rises, while $\frac{p_{L}}{w}$ rises. Hence the wage rate expressed in units of the $C$ good rises, but expressed in units of the $L$ good falls. The effect on utility of workers thus depends on relative preferences in their consumption for the two goods: if biased in favor of the $L$ good sufficiently, workers will be worse off. Treating entrepreneurial skill as the other factor, the return to the unskilled factor relative to the skilled factor in this sector $\frac{w}{w \gamma_{L}}$ goes down: an anti-Stolper-Samuelson result. The reason is that an expansion in the output of this sector is associated with an increase in rents earned by entrepreneurs in the $L$ sector, and a lowering of entry thresholds into this sector (i.e., a weakening of the reputational constraints that restrict entry). This requires entrepreneurial returns to rise relative to worker earnings, as the latter serves 
as the punishment payoff associated with a loss of reputation.

Note, however, that over the price range $p_{L} \in\left(p_{L}^{3}, p_{L}^{2}\right)$ the StolperSamuelson result does hold. Here skill premia are equalized across the two sectors, and an increase in $p_{L}$ is associated with a fall in the economy-wide skill premium, while the wage rate for unskilled workers rise. The behavior of the economy over this price range conforms to the Heckscher-Ohlin model.

The distributional effects for the other price range $\left(p_{L}^{2}, p_{L}^{1}\right)$ can be shown in more detail in Figure 4. This shows the distribution of income across agents with varying skills, and how it changes as a result of an increase in $p_{L}$. Agents with skill below the entry threshold $a_{C}$ for the $C$ sector earn the unskilled wage $w$. Between the thresholds $a_{C}$ and $a_{L}$ for the two sectors, the agents are $C$-sector entrepreneurs, earning $\gamma_{C} w a$. By definition of the threshold $a_{C}=\frac{m_{C}}{\gamma_{C}}$, it follows that the earning of a $C$-sector entrepreneur at this threshold equals $w m_{C}$, which strictly exceeds $w$ as $m_{C}>1$. Hence there is a discrete upward jump in earnings at the entry threshold for entrepreneurship. There is a similar discrete jump in earnings at the threshold $a_{L}$ for entry into the $L$ sector, owing to the difference in skill premia between the two sectors. The highest incomes accrue to entrepreneurs in the $L$-sector, who manage the largest firms in the economy. They are followed by $C$-sector entrepreneurs, who manage smaller firms, and finally workers who work as unskilled employees in both sectors.

Figure 4 shows how the distribution of income is altered following a rise in $p_{L}$ : the skill premium in the $L$-sector rises, while that in the $C$-sector falls, and the wage rate rises. For the economy as a whole the change in distribution of income consists of a rise in incomes at the top and the bottom, and a fall in incomes in the middle. Within the $L$-sector, however, inequality rises, and falls within the $C$-sector. Note that these inequality effects appear within firms.

The output and distributive impact of a rise in $p_{L}$ depend importantly on induced entry and exit effects for intermediaries, which in turn depends on the local behavior of the ability distribution. To highlight this, we simplify by assuming that the production function exhibits perfect complementarity between inputs provided by suppliers and intermediaries. Proposition 2 also allows the possibility that the density $g(a)$ takes zero value in some 


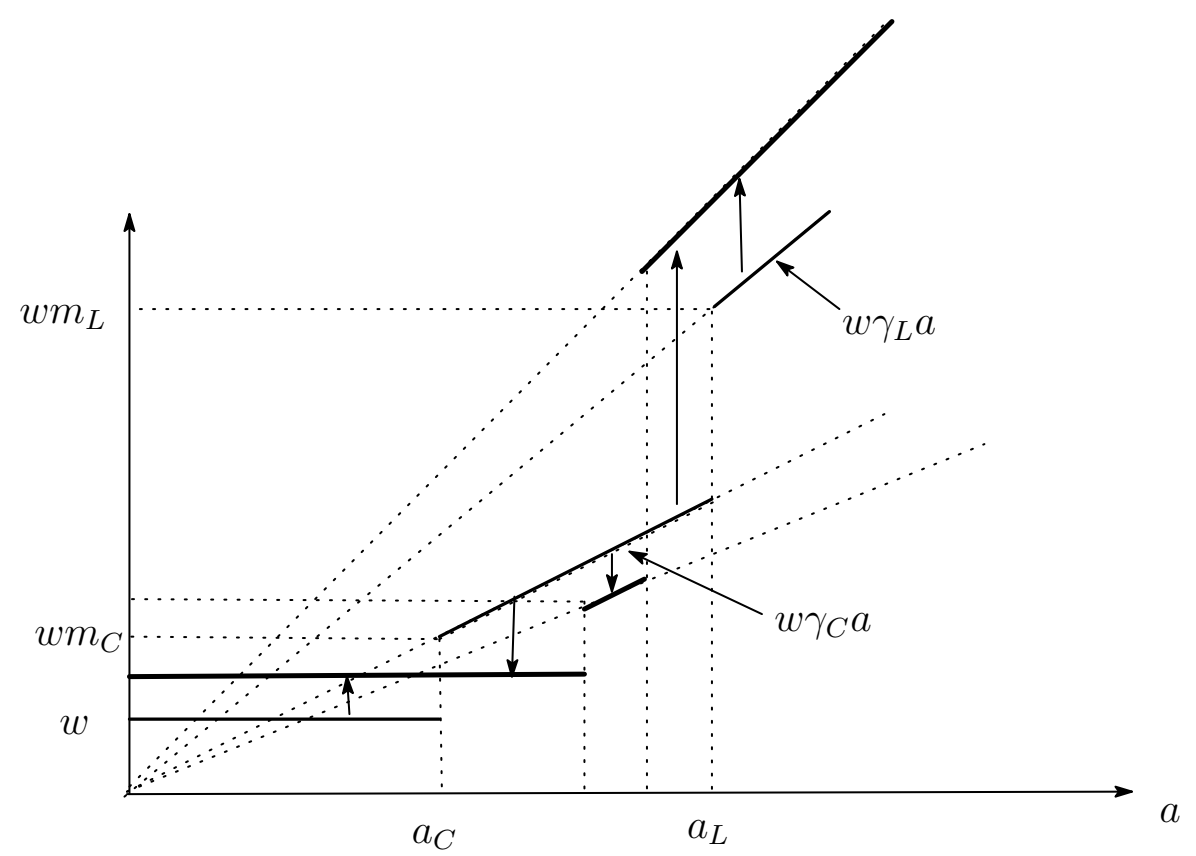

Figure 4: Income Distribution Changes Resulting from Increase in $p_{L} \in$ $\left(p_{L}^{2}, p_{L}^{3}\right)$ 
intervals ${ }^{13}$

Proposition 2 Suppose the production function in each sector $i$ exhibits perfect complementarity: $X_{i}=A_{i} \min \left\{N_{i} / \theta_{N}^{i}, a / \theta_{a}^{i}\right\}$ for the high-quality good, and $X_{i}=A_{i} \min \left\{N_{i} / \theta_{N}^{i}, z_{i} a / \theta_{a}^{i}\right\}$ for the low-quality good. Suppose also the supply-side equilibrium arises over the 'non-classical' region where the relation between $\gamma_{L}$ and $\gamma_{C}$ is downward sloping. Then an increase in $p_{L}$ results in:

(i) no change in $w, X_{L}$ and $X_{C}$ while $\gamma_{L}$ rises and $\gamma_{C}$ remains constant, if $g\left(\frac{m_{L}}{\gamma_{L}}\right)=0$ while $g\left(\frac{m_{C}}{\gamma_{C}}\right)>0$.

(ii) no change in $\gamma_{L}, X_{L}$ and $X_{C}$ while $w$ rises and $\gamma_{C}$ falls, if $g\left(\frac{m_{C}}{\gamma_{C}}\right)=0$ while $g\left(\frac{m_{L}}{\gamma_{L}}\right)>0$.

The reasoning is as follows. With perfect complementarity in production, factor intensities within firms are independent of the skill premium in that sector. Moreover, $d(a)$ is locally constant if $g(a)=0$. Then from the factor market clearing condition in the non-classical region, we obtain

$$
d \gamma_{L} / d \gamma_{C}=-\frac{\left[\frac{\theta_{N}^{C}}{\theta_{a}^{C}} a_{C}+1\right] a_{C}^{2} g\left(a_{C}\right) m_{L}}{\left[\frac{\theta_{N}^{L}}{\theta_{a}^{L}}-\frac{\theta_{N}^{C}}{\theta_{a}^{C}}\right] a_{L}^{3} g\left(a_{L}\right) m_{C}} .
$$

Figures 5 and 6 illustrate case (i), while Figures 7 and 8 illustrate case (ii). In Figure 5, a small increase in $p_{L}$ raises $\gamma_{L}$, leaving $\gamma_{C}$ and $w$ unaffected. There is 'no trickle down' in this case: the entire benefits of a rise in $p_{L}$ accrue to the middleman. Intuitively, there is no new entry of entrepreneurs into the L-sector. The demand for workers is unaltered, and so is output and the earnings of the workers.

Figure 7 shows that in case (ii) a small increase in $p_{L}$ raises $w$, but induces a decline in $\gamma_{C}$, while keeping $\gamma_{L}$ unaffected. Here none of the benefits of a rise in $p_{L}$ accrue to L-sector middlemen: they accrue to workers. With $g\left(\frac{m_{L}}{\gamma_{L}}\right)>0$, entrepreneurs move from the C-sector to the L-sector at the upper end of the ability scale in the C-sector. Since the L-sector is less skill-intensive, this raises the demand for workers and hence $w$. In turn this

\footnotetext{
${ }^{13}$ Even with $g(a)=0$ for some interval of $a$, almost all of our previous analysis is maintained. But the uniqueness of the equilibrium in Proposition 1 is violated in very special cases with $g\left(a_{L}\right)=g\left(a_{C}\right)=0$ in an equilibrium. Proposition 2 rules out this case.
} 


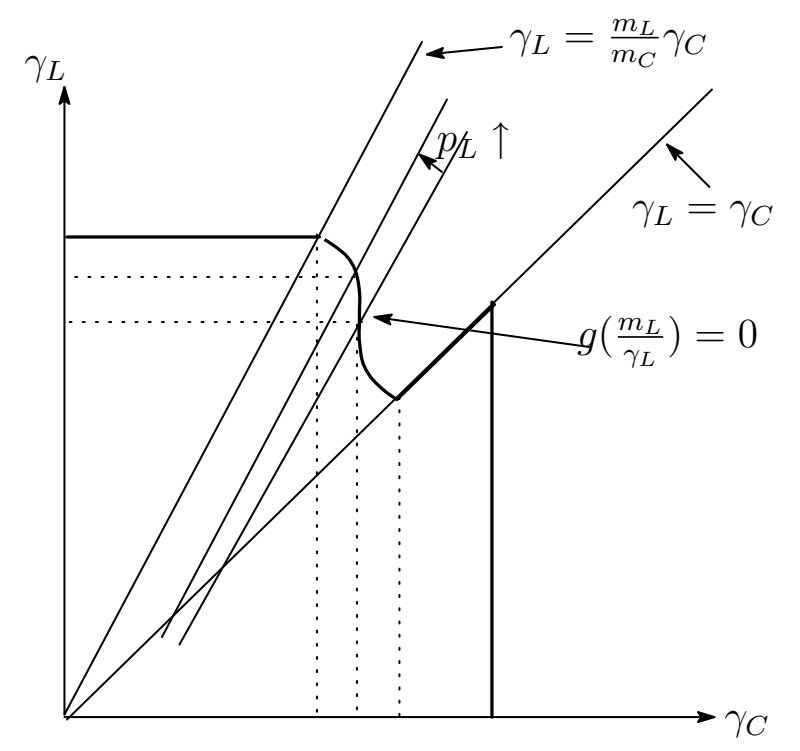

Figure 5: The case of $g\left(m_{L} / \gamma_{L}\right)=0$

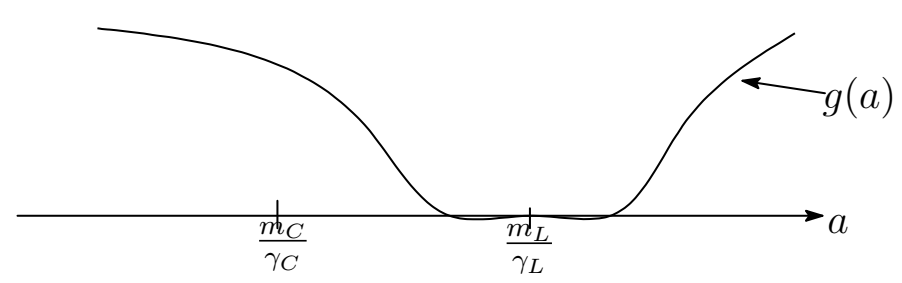

Figure 6: The case of $g\left(m_{L} / \gamma_{L}\right)=0$

causes some exit from the C-sector by entrepreneurs near the low end of the ability scale, if $g\left(\frac{m_{C}}{\gamma_{C}}\right)>0$. This offsetting effect does not arise in case (ii). Middlemen margins in the C-sector decline, and $w$ rises. The latter in turn induces a decline in entrepreneurial margins in both sectors, which chokes off the expansion in the L-sector. Eventually the output and margins in the L-sector are unaffected, with a pure distributive reallocation from C-sector entrepreneurial rents to workers.

\subsubsection{Effect of TFP Changes}

Now consider the effect of a change in TFP parameters $A_{C}, A_{L}$. These parameters have no effect on the factor market clearing condition. Their only 


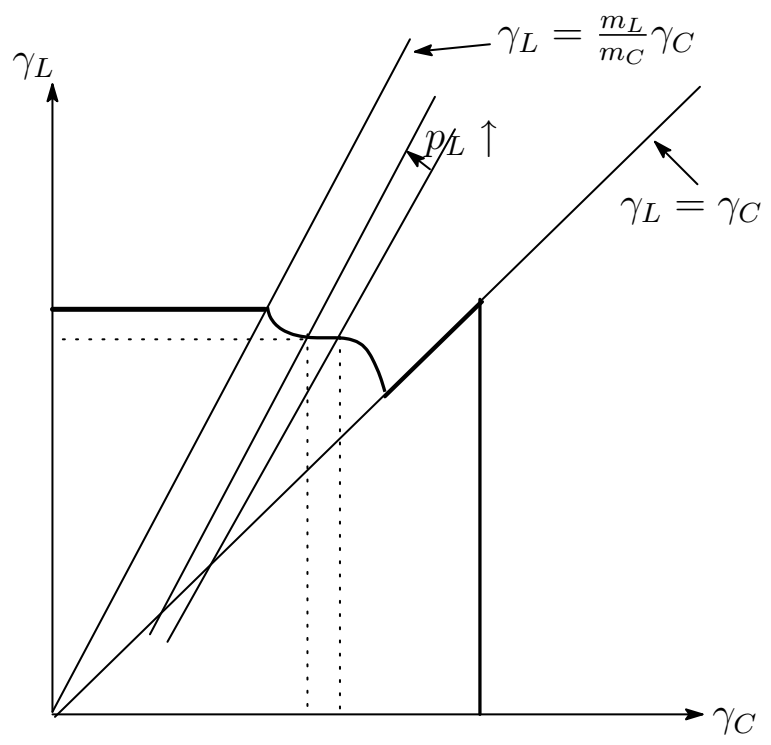

Figure 7: The case of $g\left(m_{C} / \gamma_{C}\right)=0$

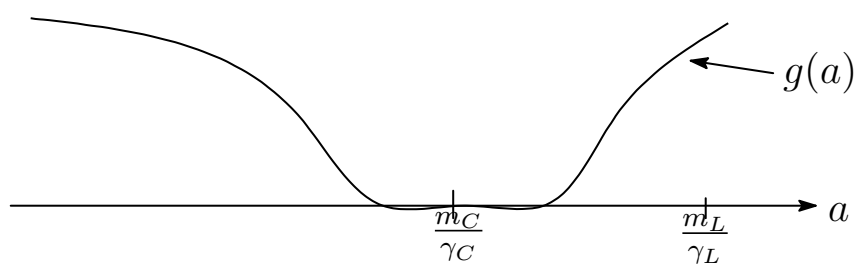

Figure 8: The case of $g\left(m_{C} / \gamma_{C}\right)=0$ 


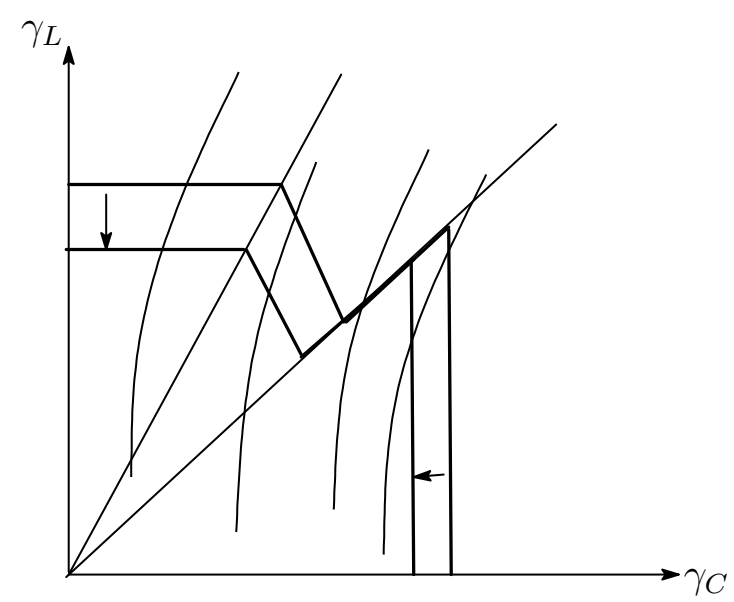

Figure 9: Effect of Increase in $\mu$ on Supply-Side Equilibrium

effect is on the price-cost relation (7): a rise in $\frac{A_{L}}{A_{C}}$ has the same effect as a rise in $p_{L}$. Hence the distributional effect of changes in relative TFP in the two sectors is qualitatively the same as the effect of a change in their relative price.

\subsubsection{Effect of Changes in Skill Endowment}

Next consider the effect of an increase in $\mu$, the proportion of agents in the economy with skills. The frontier between skill premia corresponding to the factor market-clearing condition (16) shifts inwards, owing to the resulting tightening of the market for unskilled labor. Excepting the case that $\gamma_{C}=\gamma_{L}$ is maintained before and after the change in $\mu$, both skill premia tend to fall, as shown in Figure 9. However, the effect on the relative production levels $X_{L} / X_{C}$ is complicated, we turn to this now.

Since the $C$ good is more skill-intensive, one would intuitively expect an increase in endowment of skilled labor in the economy to raise the relative production of $C$, as the Rybczynski Theorem postulates in conventional trade theory. This indeed is true in the 'classical' region with equal skill premia in the two sectors. From (17) which is independent of $\mu$, it is evident that a rise in $\mu$ leaves the skill premium unchanged. Hence the entry thresholds into the two sectors and the demand for unskilled labor from each active entrepreneur of the same skill is also unaffected. Since the $L$ sector is less skill-intensive, 
it follows that the production of the $L$ good must fall, in order to allow the market for unskilled labor to clear.

In the 'non-classical' region where the skill premium in the $L$ sector is higher, there will be an additional effect of a change in $\mu$ on skill premia in the two sectors. What turns out to matter is the change in the relative skill premia in the two sectors. An increase in $\mu$ tightens the labor market and thus tends to drive the unskilled wage higher. Since the $L$ sector is less skill-intensive, this tends to lower the skill premium in the $L$ sector by more than in the $C$ sector. However, the relative skill premium $\frac{\gamma_{L}}{\gamma_{C}}$ may still go up, if it was high enough to start with. ${ }^{14}$ In that case, we obtain a countervailing effect which can raise $\frac{X_{L}}{X_{C}}$.

To see this concretely, we consider the following example, where the density of the skill distribution does not fall too fast, and the production functions for both sectors have constant and equal elasticity of substitution between skilled and unskilled labor.

Proposition 3 Assume that $\frac{a^{2} g(a)}{d(a)}$ is increasing in a and production function for $i=L, C$ exhibit constant, equal elasticity of substitution $\kappa(\geq 0)$ :

$$
X_{i}=A_{i} F_{i}\left(N_{i}, a_{i}\right)=A_{i}\left(k_{i}^{1 / \kappa} a_{i}^{\frac{\kappa-1}{\kappa}}+N_{i}^{\frac{\kappa-1}{\kappa}}\right)^{\frac{\kappa}{\kappa-1}}
$$

with $k_{C}>k_{L}$ (to ensure Assumption 1 is satisfied). Then in the supply-side equilibrium:

(i) If $\kappa \geq 1-\frac{\log \left[\frac{k_{C}}{k_{L}}\right]}{\log \left[\frac{m_{L}}{m_{C}}\right]}$, an increase in $\mu$ has the effect of decreasing $X_{L} / X_{C}$ for any $p_{L} \in\left(p_{L}^{3}, p_{L}^{1}\right)$.

(ii) If $0 \leq \kappa<1-\frac{\log \left[\frac{k_{C}}{k_{L}}\right]}{\log \left[\frac{m_{L}}{m_{C}}\right]}$, the increase in $\mu$ has the effect of reducing $X_{L} / X_{C}$ for any $p \in\left(p_{L}^{3}, A_{C} / A_{L}\right)$. Moreover, there exists $\bar{p}_{L} \in\left(A_{C} / A_{L}, p_{L}^{1}\right)$ such that $X_{L} / X_{C}$ is increasing in $\mu$ for any $p>\bar{p}_{L}$.

The proof of this is provided in the Appendix. The Rybczynski theorem is valid if the elasticity of substitution is large (case (i)) and otherwise for

\footnotetext{
${ }^{14}$ Specifically, the tighter labor market tends to lower $\gamma_{C}$, and the effect on the relative premium $\frac{\gamma_{L}}{\gamma_{C}}$ of a change in $\gamma_{C}$ is $\frac{d\left(\frac{\gamma_{L}}{\gamma_{C}}\right)}{d \gamma_{C}}=\frac{1}{\gamma_{C}}\left[\frac{d \gamma_{L}}{d \gamma_{C}}-\frac{\gamma_{L}}{\gamma_{C}}\right]$ which is negative if $\frac{d \gamma_{L}}{d \gamma_{C}}<\frac{\gamma_{L}}{\gamma_{C}}$, i.e., the initial value of the relative premium is high enough.
} 


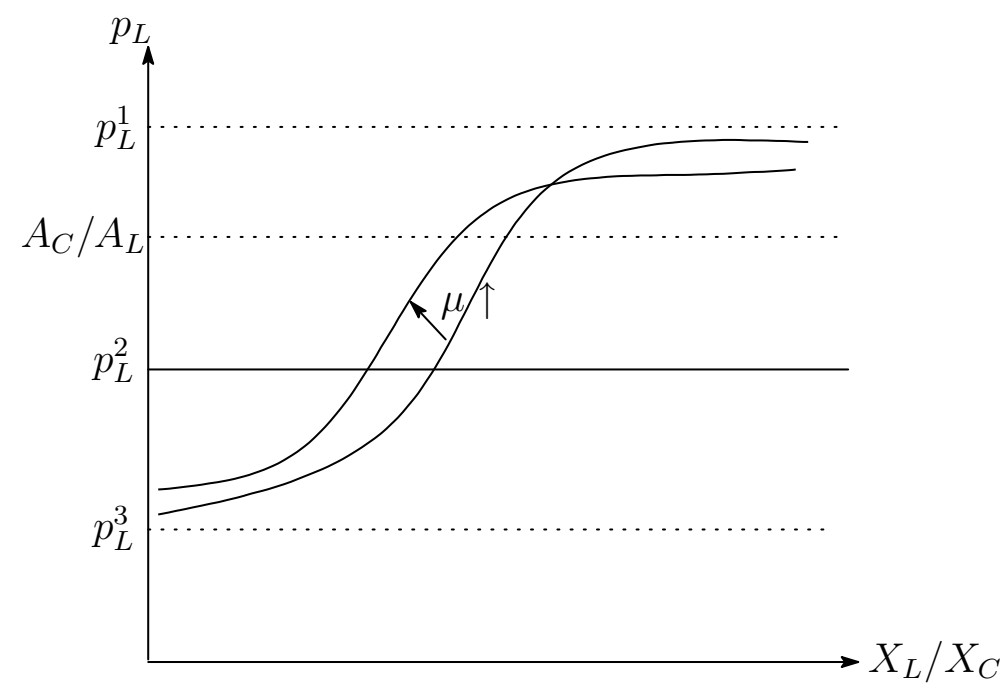

Figure 10: Effect of Increase in $\mu$ on $\frac{X_{L}}{X_{C}}$ in Supply-Side Equilibrium

values of $p_{L}$ below $\frac{A_{C}}{A_{L}}$, but not for values of $p_{L}$ close enough to $p_{L}^{1}$. In the latter case the relative skill premium in the $L$ sector is sufficiently high to start with that it increases as a result of the increase in endowment of skilled labor. This is strong enough to cause the relative production of the less skillintensive good to rise. Figure 10 provides an illustration of the effect on $\frac{X_{L}}{X_{C}}$. In the context of the open economy, this will provide an instance where the Leontief paradox appears, if a North and South country differ only in their relative endowments of skilled and unskilled labor.

\section{Autarky Equilibrium}

Now we close the model of the autarkic economy by specifying the demand side.

\subsection{Demand-Supply Condition}

There is a representative consumer with a homothetic utility function $U=$ $U\left(D_{C}, D_{L}\right)$, where $D_{C}, D_{L}$ denote consumption of the two goods. The rela- 
tive demand function is then given by

$$
D_{L} / D_{C}=\phi\left(p_{L}\right)
$$

where $\phi\left(p_{L}\right)$ is continuous and strictly decreasing in $p_{L}$. We assume that $\lim _{p_{L} \rightarrow 0} \phi\left(p_{L}\right)=\infty$ and $\lim _{p_{L} \rightarrow \infty} \phi\left(p_{L}\right)=0$.

The economy-wide equilibrium is then represented by equalization of relative supply and relative demand:

$$
D_{L} / D_{C}=\phi\left(p_{L}\right)=X_{L} / X_{C}
$$

where the dependence of relative supply $\frac{X_{L}}{X_{C}}$ on $p_{L}$ is provided by the supplyside equilibrium described in the previous section.

Proposition 4 There is a unique autarkic equilibrium, in which $p_{L} \in\left(p_{L}^{3}, p_{L}^{1}\right)$.

This follows from the fact that relative demand is continuous and strictly decreasing in $p_{L}$, while relative supply is well-defined for $p_{L} \in\left(p_{L}^{3}, p_{L}^{1}\right)$, and over this range is continuous and strictly increasing in $p_{L}$. Moreover, as $p_{L}$ tends to $p_{L}^{3}$, relative supply of the $L$ good tends to 0 while relative demand is bounded away from zero. And as $p_{L}$ tends to $p_{L}^{1}$, relative supply of $L$ tends to $\infty$, while relative demand is bounded.

The autarky equilibrium $\left(p_{L}, \gamma_{L}, \gamma_{C}, w\right)$ is characterized by conditions of profit-maximization (5), (7); the labor market clearing condition (16), and the product-market clearing condition (20). It is illustrated in Figure 11.

\subsection{Comparative Static Effect of TFP Changes}

Consider the effect of an increase in $A_{C} / A_{L}$ on the autarky equilibrium. As shown in the previous section, it causes a decrease in $X_{L} / X_{C}$ in the supplyside equilibrium for any $p_{L} \in\left(p_{L}^{3}, p_{L}^{1}\right)$. Therefore the autarky price $p_{L}$ will increase.

However the effect on skill premia $\gamma_{C}$ and $\gamma_{L}$ is more complicated. From (5) and (7), these are determined by $p_{L} A_{L} / A_{C}$. If the equilibrium level of $p_{L} A_{L} / A_{C}$ increases, the skill premia respond the same way as they do in the supply-side equilibrium when $p_{L}$ increases. Whether this is the case depends on the elasticity of substitution between the two goods on the demand-side.

Proposition 5 Let $\kappa_{D}$ denote the elasticity $-p_{L} \phi^{\prime}\left(p_{L}\right) / \phi\left(p_{L}\right)$ of relative demand at the autarkic equilibrium price $p_{L}^{*}$. Then a small increase in $A_{C} / A_{L}$ causes $p_{L}^{*} A_{L} / A_{C}$ to increase if and only if $\kappa_{D}<1$. 


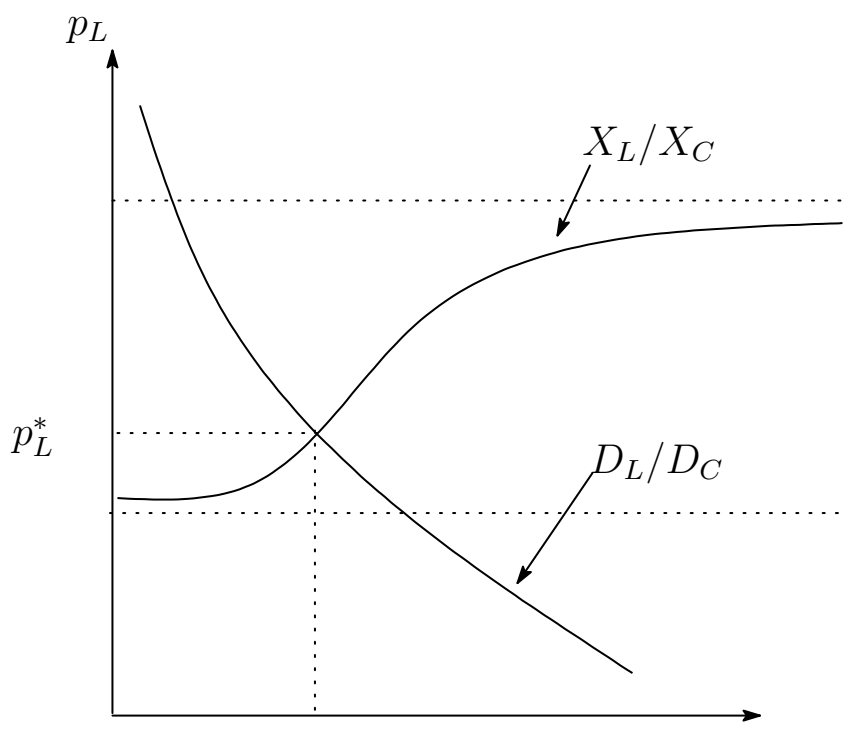

Figure 11: Autarkic Equilibrium

\section{Proof of Proposition 5}

Define $\tilde{p} \equiv p_{L} A_{L} / A_{C}$. The product market clearing condition can be written as

$$
\phi\left(\tilde{p} A_{C} / A_{L}\right) A_{C} / A_{L}=\left(X_{L} / X_{C}\right)\left(A_{C} / A_{L}\right) .
$$

Then note that from (7) and (16), $\gamma_{L}$ and $\gamma_{C}$ can be expressed as functions of $\tilde{p}$ alone. It is easily checked from the calculation of the supply-side equilibrium quantities that the right-hand-side of (21) can be expressed as a function of $\gamma_{L}, \gamma_{C}$ alone. Hence this is a function of $\tilde{p}$, i.e., conditional on the value of $\tilde{p}$, it is independent of $A_{C} / A_{L}$. Moreover it is strictly increasing in $\tilde{p}$ over the relevant range.

Since the left-hand-side of (21) is strictly decreasing in $\tilde{p}$ for any given value of $A_{C} / A_{L}$, it follows that the equilibrium value of $\tilde{p}$ is uniquely determined by this equation for any given $A_{C} / A_{L}$. The left-hand-side is locally increasing in $A_{C} / A_{L}$ if and only if $\kappa_{D}<1$, whence the equilibrium value of $\tilde{p}$ increases in $A_{C} / A_{L}$.

Hence with Cobb-Douglas utility which is associated with $\kappa_{D}=1$, changes in TFP parameters will have no effect on equilibrium skill premia. With inelastic relative demand, a ceteris paribus rise in TFP in the C-sector will 
raise skill premium in the $L$ sector and lower it in the $C$ sector. The profit maximization conditions $(5,6)$ then imply that $w$ and $\frac{p_{L}}{w}$ will rise. The distributive consequences will then be similar to those for the supply-side equilibrium when $p_{L}$ rises, illustrated in Figure 4.

\subsection{Comparative Static Effect of Changes in Skill En- dowment}

Now consider the effect on the autarky equilibrium of increasing $\mu$. Recall that the effects of this on $\frac{X_{L}}{X_{C}}$ in the supply-side equilibrium were quite complicated. However it turns out that the distributional effect on the autarkic equilibrium is quite simple: income inequality tends to fall as wages rise, while skill premia in both sectors fall.

Proposition 6 Consider a small increase in $\mu$. In the autarkic equilibrium this lowers skill premia in both sectors, while $w$ and $\frac{w}{p_{L}}$ both rise.

Proof of Proposition 6

First consider the case where the increase in $\mu$ locally reduces $X_{L} / X_{C}$, implying that equilibrium $p_{L}$ rises. Suppose that the initial price level is in $\left(p_{L}^{2}, p_{L}^{1}\right)$. Then as explained previously, taking $p_{L}$ as given, the increase in $\mu$ has the effect of decreasing $\gamma_{C}$ and $\gamma_{L}$ in the supply-side equilibrium. On the other hand, the increase in $p_{L}$ causes $\gamma_{C}$ to fall and $\gamma_{L}$ to rise. Therefore the total effect on $\gamma_{C}$ is negative. Since the equilibrium $p_{L}$ rises, the equilibrium level of $X_{L} / X_{C}$ becomes lower. However the right hand side of

$$
X_{L} / X_{C}=\frac{A_{L}}{A_{C}} \frac{\theta_{a}^{C}\left(\gamma_{C}\right)}{\theta_{a}^{L}\left(\gamma_{L}\right)} \frac{d\left(a_{L}\right)}{\left[d\left(a_{C}\right)-d\left(a_{L}\right)\right]}
$$

increases with a decrease in $\gamma_{C}$, which implies that the total effect on $\gamma_{L}$ must be negative. From (5) and (6), the effect on $w$ and $w / p_{L}$ must be positive. On the other hand, if the price level is in $\left(p_{L}^{3}, p_{L}^{2}\right)$, the increase in $\mu$ does not have a direct effect on $\gamma_{C}$ and $\gamma_{L}$ for given $p_{L}$, and the effect on both through the increase in $p_{L}$ is negative.

Next, consider the case where the increase of $\mu$ increases $X_{L} / X_{C}$ locally at the initial equilibrium. This is possible only if $p_{L} \in\left(p_{L}^{2}, p_{L}^{1}\right)$. Then the direct effect of $\mu$ taking $p_{L}$ as given is negative for both $\gamma_{L}$ and $\gamma_{C}$. On the other hand, the indirect effect through the decrease in $p_{L}$ is negative for $\gamma_{L}$ 
and positive for $\gamma_{C}$. Hence the total effect on $\gamma_{L}$ is negative. A symmetric argument to that in the previous paragraph also implies that the total effect on $\gamma_{C}$ is negative.

In sum, regardless of the effect of $\mu$ on $p_{L}$, the increase in $\mu$ makes $\gamma_{L}$ and $\gamma_{C}$ go down and $w$ and $w / p_{L}$ go up.

\section{$5 \quad$ Free Trade Equilibrium}

We are now in a position to examine the effect of trade between two countries that differ in endowments or technology. Suppose there are two countries $H$ and country $F$, the former corresponding to less developed country. We shall suppose they differ in either of two parameters: country $F$ has a higher $\mu$ the proportion of skilled agents $\left(\mu^{H}<\mu^{F}\right)$, or higher TFP in the $C$ sector $\left(A_{C}^{H}<A_{C}^{F}\right)$. In all other respects the two countries are identical. As discussed in the previous section, the differences in endowments or technology will create differences in the relative product price between the two countries in the absence of any trade.

In the free trade equilibrium (with zero transport costs), there will be a common equilibrium price $p_{L}^{T}$ in the two countries, determined by

$$
\frac{D_{L}^{H}+D_{L}^{F}}{D_{C}^{H}+D_{C}^{F}}=\frac{X_{L}^{H}+X_{L}^{F}}{X_{C}^{H}+X_{C}^{F}}
$$

where both relative demand and supplies in each country will depend on the common price. Once $p_{L}^{T}$ is determined, the respective supply-side equilibrium of each country will determine the remaining variables in each country.

\subsection{Difference in Skill Endowment}

Suppose $\mu^{H}<\mu^{F}$, and the two countries are the same on all other dimensions. From the discussion in the previous section, the ordering of relative supplies of the two goods can go either way in autarky. We first consider the 'regular' case where the relative supply of the $L$ good is lower in $F$, so country $H$ has a comparative advantage in production of the $L$ good. Let $p_{L}^{j A}$ denote the autarky price in country $j$. In most of the discussion that follows, we shall assume that the equilibrium (both under autarky and free trade) in both countries falls in the range corresponding to Case 2 where skill premia in the $L$ sector are higher. 
(1) $p_{L}^{H A}<p_{L}^{F A}$

In this case, country $H$ has comparative advantage in the production of good $L$. As a result of the free trade, the equilibrium price level $p_{L}^{T}$ will lie in $\left(p_{L}^{H A}, p_{L}^{F A}\right)$, country $H$ will export good $L$ and import good $C$. This is the same as in a standard Heckscher-Ohlin model.

The distributional effects are somewhat different, however, as illustrated in Figure 12. Trade will raise $p_{L}$ in country $H$, which as discussed previously will raise the skill premium in the $L$ sector, as well as the wage $w$. So trade liberalization tends to be accompanied by higher income inequality within the export sector of the developing country: increasing exports of the $L$ good benefits entrepreneurs in the $L$ sectors by more than it benefits unskilled workers. On the other hand, the skill premium in the $C$ sector will decline, so the effect on income inequality in the $\mathrm{H}$ country as a whole is ambiguous. See Figure 4 again.

Moreover, factor prices are not equalized as a result of free trade. With a common price ratio, country $F$ has a higher skill endowment, and a tighter labor market, so the wage rate is higher in $F$, and the skill premium in the $C$ sector is lower in $F$. Since $p_{L}$ is the same in the two countries, $\frac{p_{L}}{w}$ is higher in $H$, and the $L$ sector skill premium is also higher. Thus skill premia in both sectors are higher in $H$, while the wage rate is lower.

(2) $p_{L}^{H A}>p_{L}^{F A}$

In this case, country $H$ has the comparative advantage in production of good $C$. As a result of free trade, the equilibrium price level $p_{L}^{T}$ in the trade is in $\left(p_{L}^{F A}, p_{L}^{H A}\right)$, country $H$ exports good $C$ and imports good $L$. This corresponds to the Leontief Paradox in Heckscher-Ohlin theory. In this case, the distributional effects of trade are completely the opposite of the previous case. But $w^{F T}>w^{H T}$ is maintained.

\subsection{Differences in Technology}

Now consider the case of $A_{C}^{H}<A_{C}^{F}$. Recall that in the autarky equilibrium, an increase in $A_{C}$ raises $p_{L}$. Hence country $H$ will have a comparative advantage in good $L$, and $p_{L}^{H A}<p_{L}^{F A}$. As a result of free trade, the equilibrium price $p_{L}^{T}$ will lie in $\left(p_{L}^{H A}, p_{L}^{F A}\right)$. Country $H$ exports good $L$ and imports good $C$. 


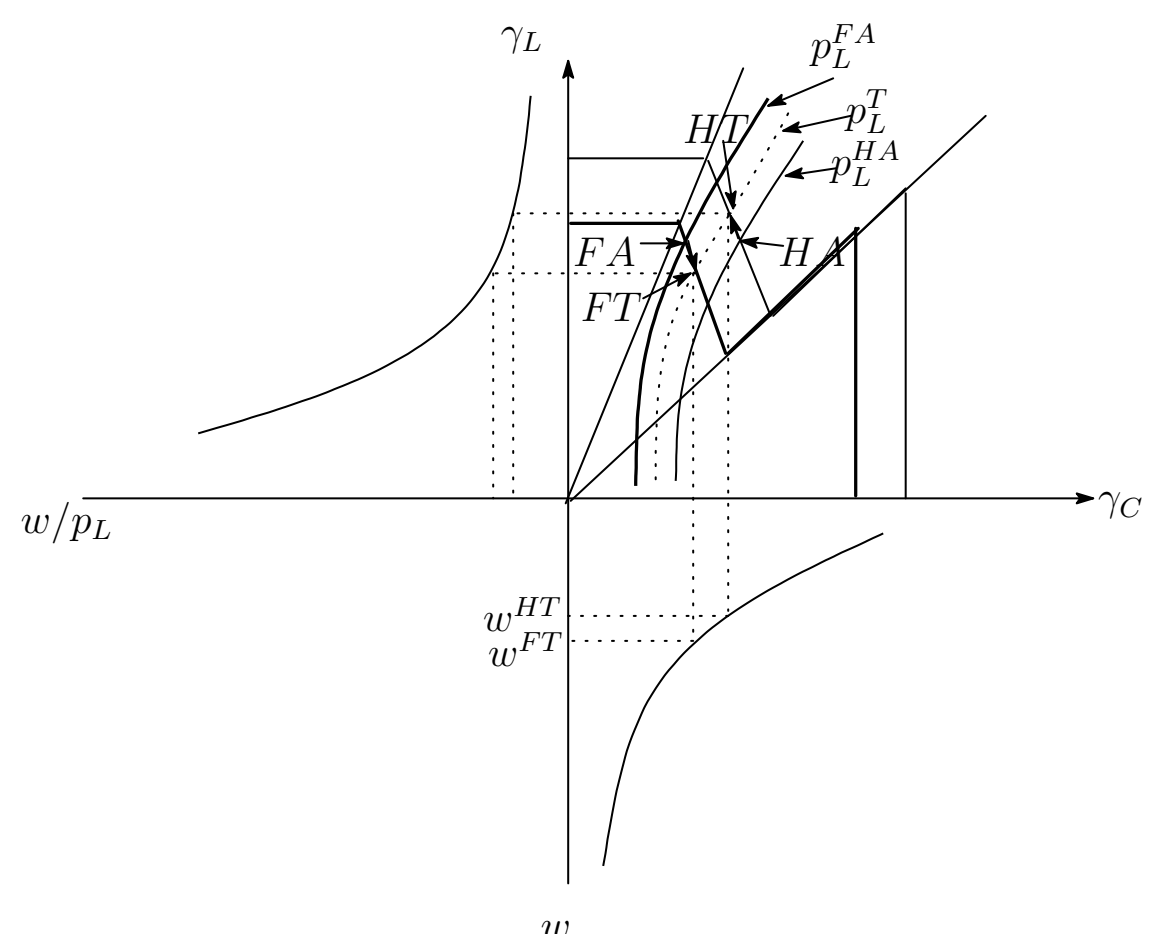

Figure 12: Comparing Free Trade with Autarky: the 'Regular' Case 
The effect of trade is thus akin to the effect of a rise in $p_{L}$ in country $H$, and a fall in country $F$. If $p_{L}^{T}$ is in $\left(p_{L}^{2 j}, p_{L}^{1 j}\right)$ for $j=H, F$, in country $H$ the skill premium in the $L$ sector rises and falls in sector $C$, the case described in Figure 4. The opposite happens in country $F$. Factor prices are not equalized in the trade equilibrium: $\gamma_{L}^{H T}>\gamma_{L}^{F T}, \gamma_{C}^{H T}<\gamma_{C}^{F T}$ and $w^{H T}<w^{F T}$.

\subsection{Welfare Effects of Trade}

The effects of trade on the equilibrium outcomes of each country are represented by the effect of trade on relative product price $p_{L}$ and thereafter on the resulting supply-side equilibrium. Hence it suffices to examine the welfare effect of changes in $p_{L}$, which can be shown to be equivalent to the following expression. ${ }^{15}$

Proposition 7 The aggregate welfare effect in country $j$ of a change in $p_{L}^{j}$ has the same sign as

$$
\left(X_{L}^{j}-D_{L}^{j}\right)+w^{j} \mu\left[\left(1-m_{C}\right) g\left(a_{C}^{j}\right) d a_{C}^{j} / d p_{L}^{j}-\left(\gamma_{L}^{j}-\gamma_{C}^{j}\right) a_{L}^{j} g\left(a_{L}^{j}\right) d a_{L}^{j} / d p_{L}^{j}\right]
$$

In addition to the standard allocative effect $X_{L}^{j}-D_{L}^{j}$, there is an additional set of welfare effects operating through the change in entry thresholds $a_{L}$ and $a_{C}$. This owes to the upward jumps in incomes at these thresholds, owing to the binding incentive constraints operating at these thresholds. A relaxation of these thresholds enables agents to transfer occupations (from being a worker to an entrepreneur, when $a_{C}$ falls) or sectors (from sector $C$ to sector $L$, when $a_{L}$ falls) and experience a discrete income gain. This explains the second and third terms in the expression above. When $a_{C}$ falls, the change in income is $-w^{j}\left(1-m_{C}\right)$ for every agent at the threshold, who is switching from being a worker to a $C$-sector entrepreneur. When $a_{L}$ falls, the change in income is proportional to the difference in skill premia between the two sectors.

In general, it is difficult to sign the sum of these income effects resulting from a change in entry thresholds following a relaxation of trade barriers. For instance, consider the cases described above where country $H$ has a comparative advantage in the $L$ good, and it is operating in the regime where the $L$ sector has a higher skill premium. Trade causes an expansion in the $L$ sector (a fall in $a_{L}$ ) which tends to raise aggregate entrepreneurial

\footnotetext{
${ }^{15}$ The Proof is postponed to the Appendix.
} 
incomes. It also causes a contraction in the $C$ sector (a rise in $a_{C}$ ) which tends to reduce aggregate income, as some $C$-sector entrepreneurs switch to becoming workers. The net effect is ambiguous. However, in the case where the moral hazard problem in the $C$ sector is negligible (i.e., $m_{C}$ approaches one), the pecuniary externality at the $a_{C}$ threshold vanishes. In that case the aggregate income effect of trade is positive for country $H$, which adds to the standard allocative benefits of trade. Conversely, the aggregate income effect is negative for country $F$, which subtracts from the allocative benefits. Hence starting from autarky, a small expansion of trade can be welfare-reducing for country $F$ ! We summarize this discussion below.

Proposition 8 Suppose country $H$ has a comparative advantage in the $L$ good, and the moral hazard problem in the $C$ sector is negligible $\left(m_{C}\right.$ approaches 1$)$, while that in the $L$ sector is non-negligible $\left(m_{L}\right.$ is bounded away from 1). Suppose also that both countries operate in the region where skill premia are not equalized across the two sectors. Then country $H$ (resp. F) experiences a welfare gain from trade in excess of (resp. less than) the standard allocative benefits. Starting from autarky, a small lowering of trade barriers will lower welfare in country $F$.

With different parameter values, these welfare results can get reversed. For instance, suppose that the moral hazard problem in the $C$ sector is nonnegligible, and approximately the same as in sector $L$ (i.e., $m_{C}$ is bounded away from 1 and $m_{L}-m_{C}$ is negligible). Then only movements in the entry threshold $a_{C}$ will generate non-negligible income effects. If country $H$ has comparative advantage in the $L$ good, trade will generate negative income effects for country $H$ and positive income effects for country $F$. Starting from autarky, small trade expansion will then lower welfare in $H$, and raise it in $F$.

\section{Offshoring}

The analysis in the previous section showed that free trade between $H$ and $F$ does not lead factor prices to be equalized. In particular, country $H$ with either a lower endowment of skilled labor or lower TFP in the $C$ sector, will end up with a lower wage rate for unskilled workers. Hence entrepreneurs in $F$ will have an incentive to organize their production by hiring workers in $H$ rather than in $F$. This section examines the implications of this type of 
offshoring. We restrict ourselves to the case where the two countries differ only in their skill endowment: $\mu_{F}>\mu_{H}$.

In addition to free trade in goods, we suppose that entrepreneurs in both sectors and countries can costlessly locate their production operations in either country. The following proposition shows that the resulting equilibrium is identical to that in the completely integrated economy with $\mu^{G} \equiv \frac{\mu^{H}+\mu^{L}}{2}$, with factor prices equal across the two economies.

Proposition 9 With free trade and costless offshoring, the equilibrium is equivalent to that in the completely integrated economy with $\mu^{G}$ proportion of skilled agents. In this equilibrium, $w^{H}=w^{F}$. With superscripts $A$ and $G$ denoting the autarky and the fully integrated equilibrium respectively, if $\gamma_{L}^{i A}>\gamma_{C}^{i A}$ for $i=H, F$,

$$
\begin{aligned}
& \text { (i) } \gamma_{L}^{F A}<\gamma_{L}^{G}<\gamma_{L}^{H A} \\
& \text { (ii) } \gamma_{C}^{F A}<\gamma_{C}^{G}<\gamma_{C}^{H A} \\
& \text { (iii) } w^{F A}>w^{G}>w^{H A}
\end{aligned}
$$

Proof of Proposition 9

Suppose that $w^{H} \neq w^{F}$ with free trade and costless offshoring. If $w^{H}<w^{F}$, all entrepreneurs would hire only workers in country $H$. However unskilled workers in country $F$ do not have the option to become entrepreneurs, and would thus be unemployed, implying $w^{F}=0$, a contradiction. Similarly, we cannot have $w^{H}>w^{F}$. With a common product price ratio $p_{L}$ and the common unskilled wage, skill premia must be equalized in each sector across the two countries. These premia must clear the market for unskilled workers in the integrated economy, i.e., satisfy (16) with $\mu^{G}$ representing the proportion of skilled agents.

As shown in the autarky equilibrium, in the region that $\gamma_{L}>\gamma_{C}$ holds in the equilibrium, the autarky levels of $\gamma^{C}$ and $\gamma^{L}$ are decreasing in $\mu$ regardless of its impact on $p_{L}$. Hence $\mu^{H}<\mu^{G}<\mu^{F}$ implies (i) and (ii). Since $\gamma_{C}$ and $w$ are inversely related, (iii) follows.

In the integrated equilibrium, the absence of any trade or offshoring costs implies that entrepreneurs are indifferent which country to locate their operations. This implies that the structure of trade is indeterminate. This 


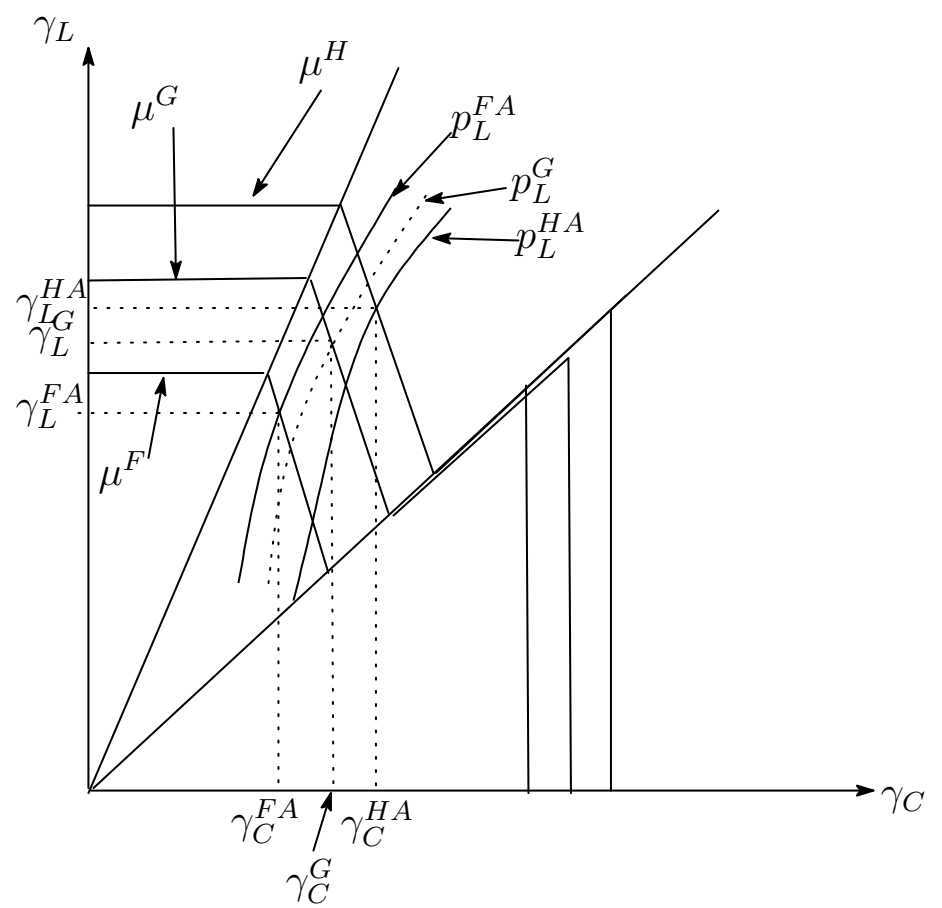

Figure 13: Comparison of Autarky with Full Integration

indeterminacy could however be resolved by the presence of small trading and offshoring costs. In either case, the difference between the total size of workers hired by country $H$ 's entrepreneurs and the total size of $H$ 's workers must be lower than that in country $F$, since $\mu^{F}>\mu^{H}$. In other words, the net size of the outsourcing must be larger for country $F$ 's entrepreneurs.

The effects of full integration relative to autarky are shown in Figure 13. Proposition 9 indicates that the distributional effect of full integration differs considerably from that of free trade alone. The latter tends to raise the skill premium in the $L$ sector in country $H$, implying $L$-sector entrepreneurs gain more than do unskilled workers. Integration on the other hand causes the skill premium in country $H$ to fall (as indicated by (i)), while the unskilled wage rises (indicated by (iii)). Hence inequality between workers and entrepreneurs within the export sector falls as a result of integration, in contrast to the effects of trade liberalization alone.

The comparison of full integration with free trade is somewhat more complicated. Suppose that under autarky country $H$ has comparative advantage 
in the $L$ good. Since $\gamma_{L}^{H T}>\gamma_{L}^{H A}>\gamma_{L}^{F A}>\gamma_{L}^{F T}$, it follows that

$$
\gamma_{L}^{H T}>\gamma_{L}^{G}>\gamma_{L}^{F T}
$$

i.e., offshoring causes skill premia in sector $L$ to fall in country $H$, and rise in country $F$. This is intuitive: the higher skill premia in this sector under free trade in country $H$ owe to the lower unskilled wage. Offshoring allows country $F$ entrepreneurs to employ unskilled workers in country $H$, erasing the disadvantage they had vis-a-vis country $H$ entrepreneurs.

However the effect of offshoring on $\gamma_{C}$ and $w$ is not so clear. If relative product prices were to remain unchanged, then offshoring would raise the unskilled wage and lower the $C$-sector skill premium in country $H$. In that case, offshoring unambiguously tends to reduce income inequality between unskilled and skilled agents in country $H$. However, offshoring could have another effect, by causing a change in $p_{L}$. This effect is not easy to sign, however. If terms-of-trade effects of offshoring are insignificant we can infer that it tends to generally improve income distribution in favor of unskilled workers in both sectors in country $H$.

\section{Concluding Comments}

We have constructed a theory of entrepreneurial or intermediary rents in a general equilibrium model of trade. These rents arise as return to key roles in financing and marketing they play. Of particular importance is the role of brand-name reputations necessary to overcome product quality moral hazard problems vis-a-vis customers. Entry thresholds, occupational and sectoral choices of all agents are endogenously determined in an otherwise fully competitive model: who becomes a supplier and who an intermediary is explained by their underlying endowment of entrepreneurial skill.

The model helps explain why trade liberalization can increase inequality of earnings between production workers and entrepreneurs in developing countries, despite comparative advantage of these countries in less skillintensive goods. Reputational considerations and limits to the size of firms reflecting fundamental moral hazard problems with regard to entrepreneurial functions such as management, finance and marketing prevent costless reallocation of factors across sectors. The shape of the distribution of entrepreneurial ability (reflecting underlying wealth distribution and financial development) in the economy determines entry and exit effects of en- 
trepreneurs, with resulting implications for concentration, markups and passthrough of effects of expanding export markets to wages of production workers or farmgate prices received by ultimate producers. With a 'thin' middle class of entrepreneurs, trade liberalization results in purely distributive effects and negligible output effects, with benefits flowing mainly to intermediaries in the form of higher markups.

These results are consistent with empirical evidence concerning effects of trade liberalization in developing countries, where Stolper-Samuelson predictions have not been borne out, and benefits of increased export opportunities for less skill-intensive goods have not trickled down appreciably to unskilled workers.

The model explains incentives for Northern countries to offshore their production to Southern countries, and predicts the distributive implications of such offshoring to be the opposite of trade liberalization. Normative implications for trade policy include the possibility of trade liberalization reducing welfare in the North owing to reduced intermediary margins in importcompeting sectors. Increasing pass-through and output responsiveness to trade liberalization requires institutional reforms that encourage entry into entrepreneurship in response to increasing profit margins.

Apart from margins earned by intermediaries, the model also generates a number of implications for size distribution of firms in different sectors, and how they are affected by relaxation in barriers to trade and offshoring. We hope these can be subject to empirical testing in future research.

\section{References}

Ahn Jaebin, Amit Khandewal and Shang-Jin Wei (2009), "Role of Intermediaries in Facilitating Trade," working paper, Columbia University.

Antras Pol, Luis Garicano and Esteban Rossi-Hansberg (2006), "Offshoring in a Knowledge Economy," Quarterly Journal of Economics, 121(1), 31-77.

Auer Raphael and Thomas Chaney (2009), "Exchange Rate Pass-Through in a Competitive Model of Pricing-to-Market," Journal of Money, Credit and Banking, 41(s1), 151-175.

Banerjee V. Abhijit and Andrew Newman (1993), "Occupational Choice and the Process of Development," Journal of Political Economy, 101(2), 274-298. Bardhan Pranab and Ken Kletzer (1984), "Quality Variations and the Choice 
between Foreign and Indigenous Goods or Technology," Journal of Development Economics, 14(3), 323-330.

Biglaiser Gary and James Friedman (1994), "Middlemen as Guarantors of Quality," International Journal of Industrial Organization, 12, 509-531.

Calvo A. Guillermo and Stanislaw Wellisz (1978), 'Supervision, Loss of Control and the Optimal Size of the Firm," Journal of Political Economy, 86(5), 943-52.

Fafchamps Marcel and Ruth Hill (2008), "Price Transmission and Trader Entry in Domestic Commodity Markets," Economic Development and Cultural Change, 56, 724-766.

Feenstra Robert (1998), "Integration of Trade and Disintegration of Production in the Global Economy," Journal of Economic Perspectives, Fall, 31-50. Feenstra Robert and Gordon Hanson (1996), "Foreign Investment Outsourcing and Relative Wages," in Economy of Trade Policy: Essays in Honour of Jagdish Bhagwati, R.C. Feenstra, G.M. Grossman and D. Irwin, eds., Cambridge MA and London: MIT Press.

(2004), "Intermediaries in Entrepot Trade: Hong Kong ReExports of Chinese Goods," Journal of Economics and Management Strategy, 13(1), 3-35.

Galor Oded and Joseph Zeira (1993), "Income Distribution and Macroeconomics," Review of Economic Studies, 60(1), 35-52

Goldberg Pinelopi and Nina Pavcnik (2007), "Distributional Effects of Globalization in Developing Countries," Journal of Economic Literature, 65, 3982.

Hallak Juan Carlos and Jagadeesh Sivadasan (2009), "Firms' Exporting Behavior under Quality Constraints," NBER Working Paper No. w14928.

Hanson, Gordon and Ann Harrison (1999), "Who Gains from Trade Reform? Some Remaining Puzzles," Journal of Development Economics, 59(1), 12554 .

Keren Michael and David Levhari (1983), "The Internal Organization of the Firm and the Shape of Average Cost," Bell Journal of Economics, 14(2), 474-86

Kremer Michael (1993), "The O-Ring Theory of Economic Development," Quarterly Journal of Economics, 108, 551-575.

Kremer Michael and Eric Maskin (2003), "Globalization and Inequality," mimeo, Department of Economics, Harvard University. 
Lucas Robert. E. Jr. (1978), "On the Size Distribution of Business Firms," The Bell Journal of Economics, 9(2), 508-523.

Manasse Paolo and Alessandro Turrini (2001), "Trade, Wages and Superstars," Journal of International Economics, 54(1), 97-117.

McMillan Margeret, Dani Rodrik and Karen Welch (2002), "When Economic Reform Goes Wrong: Cashews in Mozambique," NBER Working Paper no. 9117, August 2002.

Morisset Jacques (1998), "Unfair Trade? The Increasing Gap Between World and Domestic Prices in Commodity Markets during the Past 25 Years," World Bank Research Observer, 12 (3), 503-526.

Qian Yingyi (1994), "Incentives and Loss of Control in an Optimal Hierarchy," Review of Economic Studies, 61(3), 527-44.

Sutton John (2007), "Quality, Trade and the Moving Window," Economic Journal, 117(524), F469-498.

Van Zandt Timothy and Roy Radner (2001), "Real-Time Decentralized Information Processing and Returns to Scale," Economic Theory, 17(3), 545-75.

Williamson E. Oliver (1967), "Hierarchical Control and Optimal Firm Size,' Journal of Political Economy, 75, 123-138.

Winters L. Alan, Nel McCulloch and Andrew McKay (2004), "Trade Liberalization and Poverty: The Evidence So Far," Journal of Economic Literature, $42(1), 72-115$. 


\title{
Appendix A: Effects of Alternative Assump- tions Concerning Moral Hazard
}

\author{
A1: The Case of $m_{C}>m_{L}$
}

Here we explain the consequences of the situation where the more skillintensive good is more subject to moral hazard. The nature of the supply-side equilibrium is altered: the non-classical region may no longer exist. To see this, consider the case where both the entry threshold and the entrepreneurial margin is higher in the $C$ sector. Consider the effect of an increase in $\gamma_{L}$ on the unskilled labor market clearing condition. The lowering of the entry threshold into the $C$ sector causes a shift of entrepreneurs from $L$ into $C$. Since $C$ is less skill intensive than $L$, this causes a slacking in the labor market, and the wage rate drops. This in turn increases labor intensity in both sectors, which tightens the labor market. If the former effect dominates, the relationship between $\gamma_{C}$ and $\gamma_{L}$ would be upward-sloping. In the case of a Leontief production function, the latter effect vanishes and the relationship between the margins in the two sectors must be upward sloping. The resulting $\gamma_{C}-\gamma_{L}$ relation is shown in Figure 14. In this case, it is evident that the standard Stolper-Samuelson results always hold: an increase in $p_{L}$ must always reduce the skill premium.

\section{A2: Differences in $m_{L}$ and $m_{C}$ between country $H$ and F}

Now we examine the case that the values of $m_{L}$ and $m_{C}$ differ between two countries, owing to differential regulations or their enforcement. It is natural to consider the case where the North has higher standards and enforces them more strongly. Suppose also that both goods are subject to a common level of moral hazard in the North, while in the South the L good is more subject to moral hazard: $m_{L}^{H}>m_{C}^{H}>m_{L}^{F}=m_{C}^{F} \cdot m^{F}$ thus denotes the common level of moral hazard in $F$.

First we consider autarkic equilibrium in the North, with a common level $m$ of moral hazard in both sectors. Our analysis of the factor market conditions are classified into three cases, as follows.

Case 1: $\gamma_{L}>\gamma_{C}$ 


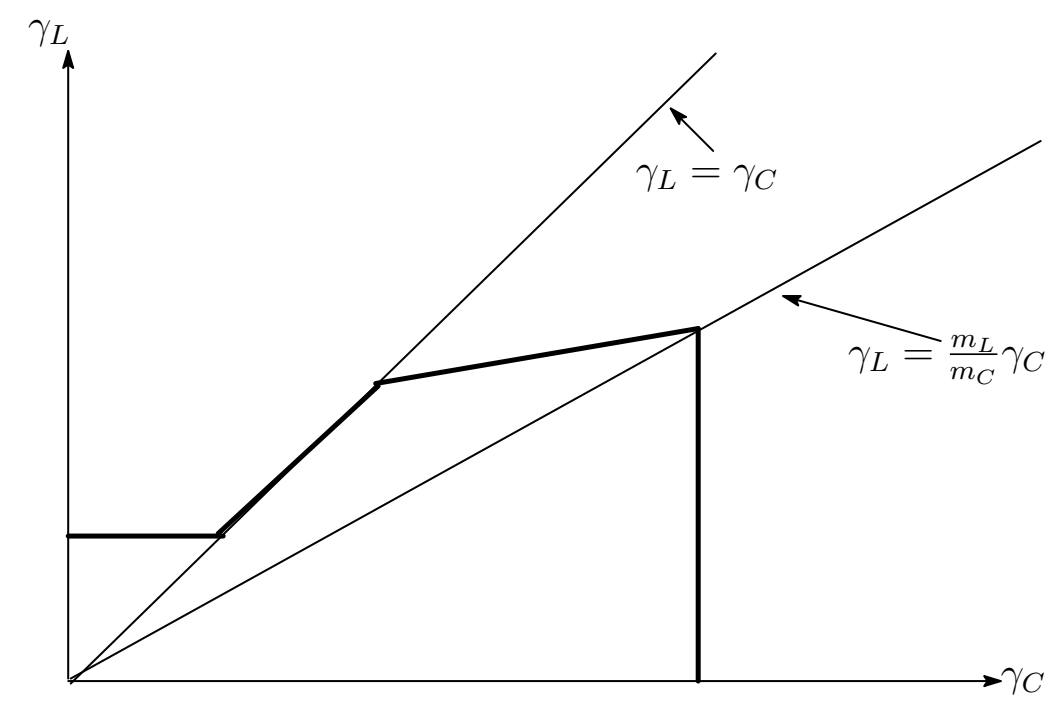

Figure 14: The case of $m_{C}>m_{L}$ with perfect complementary production function

$\gamma_{L}>\gamma_{C}$ implies that entrepreneurship in sector $L$ is more profitable than in sector $C$. The entry threshold for this sectors is also lower, as $\frac{m}{\gamma_{L}}<\frac{m}{\gamma_{C}}$. Hence all those with skill above $\frac{m}{\gamma_{L}}$ will enter the $L$ sector, and those below will become unskilled workers. Clearing of the labor market requires

$$
\mu\left[\frac{\theta_{N}^{L}\left(\gamma_{L}\right)}{\theta_{a}^{L}\left(\gamma_{L}\right)}\right] d\left(a_{L}\right)=\mu G\left(a_{L}\right)+(1-\mu) .
$$

The production levels will be $X_{C}=0, X_{L}=\mu A_{L} d\left(a_{L}\right) / \theta_{a}^{L}\left(\gamma_{L}\right)$.

Case 2: $\gamma_{C}=\gamma_{L}$

$\gamma_{L}=\gamma_{C}=\gamma$, say, implies that entrepreneurs are indifferent between the two sectors. With $a_{L}=m / \gamma=a_{C}$. Hence agents with $a \geq a_{L}=a_{C}$ can enter either of the two sectors. Denoting the production levels by $X_{L}, X_{C}$ respectively, the factor market clearing conditions are

$$
\begin{gathered}
{\left[\theta_{N}^{L}(\gamma) / A_{L}\right] X_{L}+\left[\theta_{N}^{C}(\gamma) / A_{C}\right] X_{C}=\mu G\left(a_{C}\right)+(1-\mu)} \\
{\left[\theta_{a}^{L}(\gamma) / A_{L}\right] X_{L}+\left[\theta_{a}^{C}(\gamma) / A_{C}\right] X_{C}=\mu d\left(a_{C}\right)}
\end{gathered}
$$


These equations are equivalent to

$$
\begin{gathered}
X_{L}=A_{L} \frac{\theta_{a}^{C}(\gamma)\left[\mu G\left(a_{C}\right)+(1-\mu)\right]-\theta_{N}^{C}(\gamma) \mu d\left(a_{C}\right)}{\theta_{N}^{L}(\gamma) \theta_{a}^{C}(\gamma)-\theta_{N}^{C}(\gamma) \theta_{a}^{L}(\gamma)} \\
X_{C}=A_{C} \frac{-\theta_{a}^{L}(\gamma)\left[\mu G\left(a_{C}\right)+(1-\mu)\right]+\theta_{N}^{L}(\gamma) \mu d\left(a_{C}\right)}{\theta_{N}^{L}(\gamma) \theta_{a}^{C}(\gamma)-\theta_{N}^{C}(\gamma) \theta_{a}^{L}(\gamma)} .
\end{gathered}
$$

$X_{L} \geq 0$ implies

$$
\mu\left[\frac{\theta_{N}^{C}(\gamma)}{\theta_{a}^{C}(\gamma)}\right] d(m / \gamma) \leq \mu G(m / \gamma)+(1-\mu)
$$

$X_{C} \geq 0$ implies

$$
\mu\left[\frac{\theta_{N}^{L}(\gamma)}{\theta_{a}^{L}(\gamma)}\right] d(m / \gamma) \geq \mu G(m / \gamma)+(1-\mu)
$$

Two inequalities provide lower and upper bounds on the common premium rate $\gamma$.

Case 3: $\gamma_{C}>\gamma_{L}$

$\gamma_{C}>\gamma_{L}$ implies that sector $C$ is more profitable. Also the entry threshold in sector $C$ is lower. In this case no entrepreneur enters sector $L$. Those with skill $a \geq a_{C}$ enter sector $C$, the rest become workers. The labor market condition is

$$
\mu\left[\frac{\theta_{N}^{C}\left(\gamma_{C}\right)}{\theta_{a}^{C}\left(\gamma_{C}\right)}\right] d\left(a_{C}\right)=\mu G\left(a_{C}\right)+(1-\mu) .
$$

The production levels are

$$
\begin{gathered}
X_{L}=0 \\
X_{C}=\mu A_{C} d\left(a_{C}\right) / \theta_{a}^{C}\left(\gamma_{C}\right) .
\end{gathered}
$$

Figure 15 shows a typical example of the supply-side equilibrium and how it is affected by a decrease in $p_{L}$.

We are now in a position to describe the effects of lowering the common level of moral hazard $m$ in the autarkic equilibrium.

Lemma 2 A decrease in $m=m_{C}=m_{L}$ has the effect of raising $p_{L}$ and $w$, and lowering $\gamma_{L}=\gamma_{C}$ in the autarkic equilibrium. 


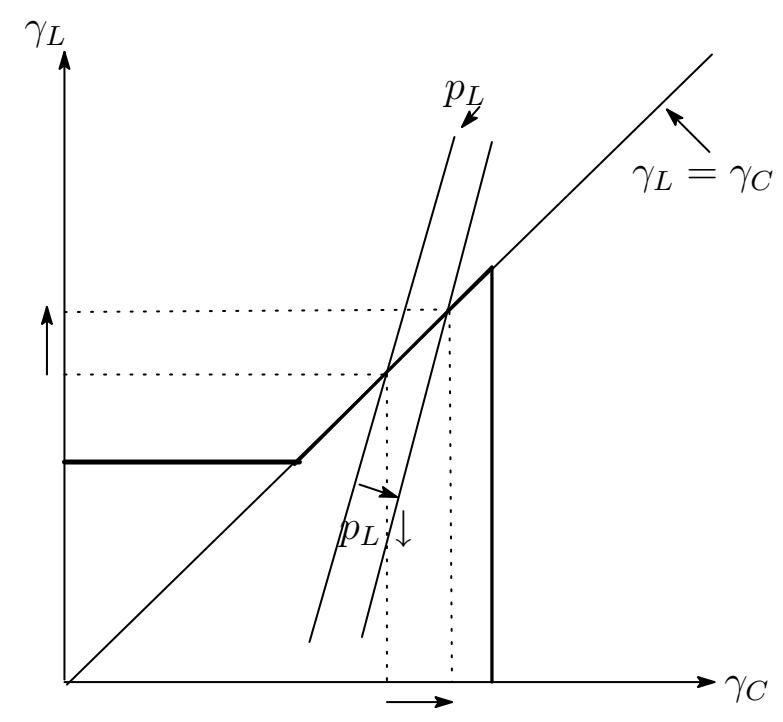

Figure 15: Autarkic Equilibrium with $m_{C}=m_{L}=m$

\section{Proof 2}

Taking $p_{L}$ as fixed, consider the effect of a decrease in $m$ on the supply-side equilibrium. As long as $p_{L}$ is in the region where $X_{L}>0$ and $X_{C}>0$, the change in $m$ does not have any effect on $\gamma=\gamma_{L}=\gamma_{C}$. On the other hand, the decrease in $m$ has the effect of increasing $X_{C}$ and reducing $X_{L}$, since the reduction of $a_{C}$ induces a shift from workers to entrepreneurs, analogous to a conventional Rybczynski effect. The increase in the relative supply of $X_{C}$ induces $p_{L}$ to go up in the autarkic equilibrium. The effect on $w$ and $\gamma$ follows from the standard Stolper-Samuelson logic. QED

This lemma indicates that the developed country with a lower $m$ and higher $\mu$ tends to have a comparative advantage in the $C$ good.

Now turn to country $H$ where $m_{L}^{H}>m_{C}^{H}$. Initially suppose that the supply-side equilibrium is in the non-classical region $\frac{m_{L}}{m_{C}} \gamma_{C}>\gamma_{L}>\gamma_{C}$. Then consider the effect of an increase in $m_{L}$, taking $m_{C}$ as given. The downwardsloping relation between $\gamma_{L}$ and $\gamma_{C}$ (satisfying the factor market clearing condition) is shifted outwards. Taking $p_{L}$ as given, the increase in $m_{L}$ raises both $\gamma_{L}$ and $\gamma_{C}$. But in order for the factor market clearing condition to be 
satisfied, $a_{L}=m_{L} / \gamma_{L}$ must rise. It implies an increase in

$$
X_{C}=\mu A_{C}\left[d\left(a_{C}\right)-d\left(a_{L}\right)\right] / \theta_{a}^{C}\left(\gamma_{C}\right) .
$$

On the other hand, the factor market condition is equivalent to

$$
\theta_{N}^{L}\left(\gamma_{L}\right) X_{L}+\theta_{N}^{C}\left(\gamma_{C}\right) X_{C}=\mu G\left(\frac{m_{C}}{\gamma_{C}}\right)+(1-\mu) .
$$

This implies that $X_{L}$ must decrease. Then the following result is straightforward.

Lemma 3 Taking $m_{C}$ as given, the increase in $m_{L}$ (in the region of $m_{L}>$ $\left.m_{C}\right)$ has the effect of raising $p_{L}$ in autarkic equilibrium.

Now let us consider the case of $m_{L}^{H}>m_{C}^{H}>m_{L}^{F}=m_{C}^{F}=m^{F}$. If two countries are identical in all other ways, from the above two lemmas, the pattern of comparative advantage is ambiguous. Consider the effect of the change in $m_{C}^{H}$, everything else remaining the same. If $m^{F}$ is very close to $m_{C}^{H}$, country $H$ has a comparative advantage in $C$. On the other hand, if $m_{C}^{H}$ is sufficiently close to $m_{L}^{H}$, the comparative advantage is reversed.

Assume that parameters are such that country $F$ has a comparative advantage in $C$. Suppose that the autarky equilibrium in $H$ occurs in nonclassical region with $\gamma_{L}>\gamma_{C}$. Then as a result of the trade, inequality expands in both sectors in $F$, and inequality expands in the $L$ sector, but shrinks within the $C$ sector in $H$. Depending on the relative size of the two sectors in $H$, trade may expand inequality in both countries. Figure 16 shows one example.

The aggregate welfare effect for the increase in $p_{L}$ in $F$ is

$$
\left(X_{L}^{F}-D_{L}^{F}\right)+w^{F} \mu\left[\left(1-m_{C}^{F}\right) g\left(a_{C}^{F}\right) d a_{C}^{F} / d p_{L}^{F}\right]<0
$$

implying that $H$ benefits from the trade which reduce $p_{L}$. On the other hand, for country $H$, it is

$\left(X_{L}^{H}-D_{L}^{H}\right)+w^{H} \mu\left[\left(1-m_{C}^{H}\right) g\left(a_{C}^{H}\right) d a_{C}^{H} / d p_{L}^{H}-\left(\gamma_{L}^{H}-\gamma_{C}^{H}\right) a_{L}^{H} g\left(a_{L}^{H}\right) d a_{L}^{H} / d p_{L}^{H}\right]$.

This is ambiguous, as analyzed before, with both the shift from $C$ 's entrepreneurs to workers, and from $C$ 's entrepreneurs to $L$ 's one bringing the opposite effect on welfare. Consider the case of $m_{L}^{H}>m_{C}^{H}=m^{F}=1$, and the difference between $\mu^{H}$ and $\mu^{F}$ is so large that $H$ has comparative advantage for $L$. Then both countries certainly benefit from the trade, even though it may expand inequality in both countries. 


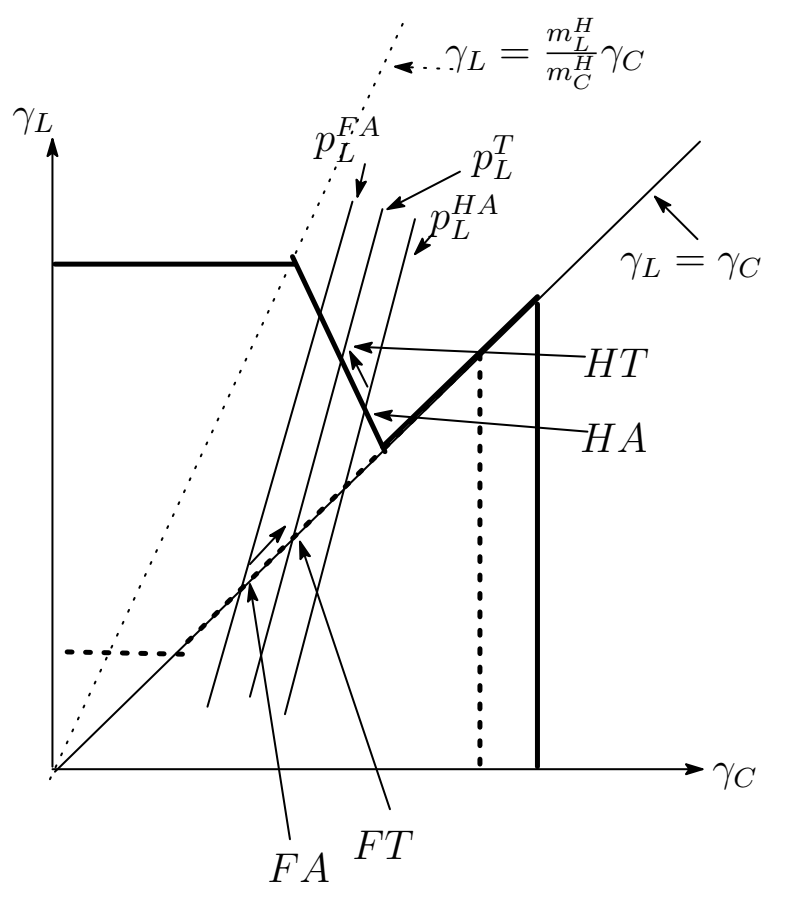

Figure 16: The case of $m_{L}^{H}>m_{C}^{H}>m_{L}^{F}=m_{C}^{F}=m^{F}$ 


\section{Appendix B: Proofs}

Proof of Proposition 2

The argument for changes in margins and wages has already been explained in the text. To derive the results concerning outputs, note that in either of the two cases, the effect on output (upon using $X_{L}=\mu A_{L} d\left(a_{L}\right) / \theta_{a}^{L}$ and $\left.X_{C}=\mu A_{C}\left[d\left(a_{C}\right)-d\left(a_{L}\right)\right] / \theta_{a}^{C}:\right)$

$$
\begin{gathered}
d X_{L} / d p_{L}=-\mu A_{L} a_{L} g\left(a_{L}\right) d a_{L} / d p_{L} / \theta_{a}^{C} \\
d X_{C} / d p_{L}=-\mu A_{C}\left[a_{C} g\left(a_{C}\right) d a_{C} / d p_{L}-a_{L} g\left(a_{L}\right) d a_{L} / d p_{L}\right] / \theta_{a}^{C} .
\end{gathered}
$$

Using the price-cost conditions and the perfect complementarity of the technology, one can obtain:

$$
\begin{gathered}
d a_{C} / d p_{L}=\frac{A_{L}\left(\theta_{N}^{C}+\gamma_{C} \theta_{a}^{C}\right)}{A_{L} \theta_{a}^{C} p_{L}\left(\gamma_{C} / a_{C}\right)+A_{C} \theta_{a}^{L}\left(\gamma_{L} / a_{L}\right) \frac{\left[\frac{\theta_{N}^{C}}{\theta_{a}^{C}} a_{C}+1\right] g\left(a_{C}\right)}{\left[\frac{\theta_{N}^{L}}{\theta_{a}^{L}}-\frac{\theta_{N}^{C}}{\theta_{a}^{C}}\right] a_{L} g\left(a_{L}\right)}} \\
d a_{L} / d p_{L}=-\frac{\left[\frac{\theta_{N}^{C}}{\theta_{a}^{C}} a_{C}+1\right] g\left(a_{C}\right)}{\left[\frac{\theta_{N}^{L}}{\theta_{a}^{L}}-\frac{\theta_{N}^{C}}{\theta_{a}^{C}}\right] a_{L} g\left(a_{L}\right)} \frac{A_{L}\left(\theta_{N}^{C}+\gamma_{C} \theta_{a}^{C}\right)}{A_{L} \theta_{a}^{C} p_{L}\left(\gamma_{C} / a_{C}\right)+A_{C} \theta_{a}^{L}\left(\gamma_{L} / a_{L}\right) \frac{\left[\frac{\theta_{N}^{C}}{\theta_{C}^{C}} a_{C}+1\right] g\left(a_{C}\right)}{\left[\frac{\theta_{N}^{L}}{\theta_{a}^{L}}-\frac{\theta_{N}^{C}}{\theta_{a}^{C}}\right] a_{L} g\left(a_{L}\right)}}
\end{gathered}
$$

Hence the effect on each output (depending upon the size of the density) reduces to

$$
g\left(a_{C}\right) d a_{C} / d p_{L}=\frac{A_{L}\left(\theta_{N}^{C}+\gamma_{C} \theta_{a}^{C}\right)}{\frac{A_{L} \theta_{a}^{C} p_{L}\left(\gamma_{C} / a_{C}\right)}{g\left(a_{C}\right)}+A_{C} \theta_{a}^{L}\left(\gamma_{L} / a_{L}\right) \frac{\left[\frac{\theta_{N}^{C}}{\theta_{a}^{C}} a_{C}+1\right]}{\left[\frac{\theta_{N}^{L}}{\theta_{a}^{L}}-\frac{\theta_{N}^{C}}{\theta_{a}^{C}}\right] a_{L} g\left(a_{L}\right)}}
$$

from which the result follows.

Proof of Proposition 3

\section{Step 1}

(i)If $\kappa \geq 1, d\left[\gamma_{L} / \gamma_{C}\right] / d \gamma_{C}=d\left[\lambda\left(\gamma_{C} ; p_{L}, \frac{A_{C}}{A_{L}}\right) / \gamma_{C}\right] / d \gamma_{C}>0$ for any $\gamma_{C}$ so that $\lambda\left(\gamma_{C} ; p_{L}, \frac{A_{C}}{A_{L}}\right) / \gamma_{C} \geq 1$ 
(ii)If $\kappa<1, d\left[\gamma_{L} / \gamma_{C}\right] / d \gamma_{C}=d\left[\lambda\left(\gamma_{C} ; p_{L}, \frac{A_{C}}{A_{L}}\right) / \gamma_{C}\right] / d \gamma_{C}>0$ if and only if $p_{L}<A_{C} / A_{L}$ (and equivalently $\left.\gamma_{L} / \gamma_{C}<\left(\frac{k_{C}}{k_{L}}\right)^{\frac{1}{1-\kappa}}\right)$.

Proof of Step 1

From (7),

$$
d\left[\gamma_{L} / \gamma_{C}\right] / d \gamma_{C}=\left(1 / \gamma_{C}\right)\left[\frac{\gamma_{L}+\frac{\theta_{N}^{L}}{\theta_{a}^{L}}}{\gamma_{C}+\frac{\theta_{N}^{C}}{\theta_{a}^{C}}}-\frac{\gamma_{L}}{\gamma_{C}}\right],
$$

which means that $d\left[\gamma_{L} / \gamma_{C}\right] / d \gamma_{C}>0$ if and only if

$$
\frac{\gamma_{L} \theta_{a}^{L}\left(\gamma_{L}\right)}{\theta_{N}^{L}\left(\gamma_{L}\right)}<\frac{\gamma_{C} \theta_{a}^{C}\left(\gamma_{C}\right)}{\theta_{N}^{C}\left(\gamma_{C}\right)}
$$

Under this production function in the proposition,

$$
\frac{\theta_{a}^{i}\left(\gamma_{i}\right)}{\theta_{N}^{i}\left(\gamma_{i}\right)}=\left(\gamma_{i}\right)^{-\kappa} k_{i}
$$

and

$$
p_{L}=\frac{A_{C}}{A_{L}} \frac{\theta_{N}^{L}\left(\gamma_{L}\right)+\gamma_{L} \theta_{a}^{L}\left(\gamma_{L}\right)}{\theta_{N}^{C}\left(\gamma_{C}\right)+\gamma_{C} \theta_{a}^{C}\left(\gamma_{C}\right)}=\frac{A_{C}}{A_{L}}\left[\frac{k_{L} \gamma_{L}^{1-\kappa}+1}{k_{C} \gamma_{C}^{1-\kappa}+1}\right]^{\frac{1}{1-\kappa}} .
$$

In the case of $\kappa \geq 1$ and $\gamma_{L} \geq \gamma_{C}$,

$$
\frac{\gamma_{L} \theta_{a}^{L}\left(\gamma_{L}\right)}{\theta_{N}^{L}\left(\gamma_{L}\right)}=\left(\gamma_{L}\right)^{1-\kappa} k_{L}<\left(\gamma_{C}\right)^{1-\kappa} k_{C}=\frac{\gamma_{C} \theta_{a}^{C}\left(\gamma_{C}\right)}{\theta_{N}^{C}\left(\gamma_{C}\right)}
$$

implying $d\left[\gamma_{L} / \gamma_{C}\right] / d \gamma_{C}>0$. In the case of $\kappa<1$,

$$
\frac{\gamma_{L} \theta_{a}^{L}\left(\gamma_{L}\right)}{\theta_{N}^{L}\left(\gamma_{L}\right)}<\frac{\gamma_{C} \theta_{a}^{C}\left(\gamma_{C}\right)}{\theta_{N}^{C}\left(\gamma_{C}\right)}
$$

if and only if $\gamma_{L} / \gamma_{C}<\left(\frac{k_{C}}{k_{L}}\right)^{\frac{1}{1-\kappa}}$ which is equivalent to $p_{L}<A_{C} / A_{L}$.

\section{Step 2}

(i) If $\kappa \geq 1-\frac{\log \left[\frac{k_{C}}{k_{L}}\right]}{\log \left[\frac{m_{L}}{m_{C}}\right]}$,

$$
d\left[\lambda\left(\gamma_{C} ; p_{L}, \frac{A_{C}}{A_{L}}\right) / \gamma_{C}\right] / d \gamma_{C}>0
$$

holds for $p_{L} \in\left[p_{L}^{2}, p_{L}^{1}\right)$. 
(ii) If $0 \leq \kappa<1-\frac{\log \left[\frac{k_{C}}{k_{L}}\right]}{\log \left[\frac{m_{L}}{m_{C}}\right]}$, for any $p_{L}<A_{C} / A_{L}$,

$$
d\left[\lambda\left(\gamma_{C} ; p_{L}, \frac{A_{C}}{A_{L}}\right) / \gamma_{C}\right] / d \gamma_{C}>0
$$

and for any $p_{L}>A_{C} / A_{L}$,

$$
d\left[\lambda\left(\gamma_{C} ; p_{L}, \frac{A_{C}}{A_{L}}\right) / \gamma_{C}\right] / d \gamma_{C}<0 .
$$

Proof of Step 2

First suppose that $\frac{m_{L}}{m_{C}} \leq\left[\frac{k_{C}}{k_{L}}\right]^{1 /(1-\kappa)}$ and $\kappa<1$, which are equivalent to $1>\kappa \geq 1-\frac{\log \left[\frac{k_{C}}{k_{L}}\right]}{\log \left[\frac{m_{L}}{m_{C}}\right]}$. If $p_{L} \in\left(p_{L}^{2}, p_{L}^{1}\right)$, since $m_{L} / m_{C}>\gamma_{L} / \gamma_{C} \geq 1$ is satisfied in an equilibrium of supply-side, it implies $\gamma_{L} / \gamma_{C}<\left(\frac{k_{C}}{k_{L}}\right)^{1 /(1-\kappa)}$ (or $\left.p_{L}<\frac{A_{C}}{A_{L}}\right)$. From (ii) of Step 1, this means that

$$
d\left[\lambda\left(\gamma_{C} ; p_{L}, \frac{A_{C}}{A_{L}}\right) / \gamma_{C}\right] / d \gamma_{C}>0
$$

holds for $p_{L} \in\left[p_{L}^{2}, p_{L}^{1}\right)$. From (i) of Step 1, this inequality also holds for $\kappa \geq 1$. This completes the proof of (i).

Next take $0 \leq \kappa<1-\frac{\log \left[\frac{k_{C}}{k_{L}}\right]}{\log \left[\frac{m_{L}}{m_{C}}\right]}$. From (ii) in Step 1, for any $p_{L}<A_{C} / A_{L}$,

$$
d\left[\lambda\left(\gamma_{C} ; p_{L}, \frac{A_{C}}{A_{L}}\right) / \gamma_{C}\right] / d \gamma_{C}>0
$$

and for any $p_{L}>A_{C} / A_{L}$,

$$
d\left[\lambda\left(\gamma_{C} ; p_{L}, \frac{A_{C}}{A_{L}}\right) / \gamma_{C}\right] / d \gamma_{C}<0
$$

This completes the proof of (ii).

\section{Step 3}


Taking $p_{L} \in\left(p_{L}^{1}, p_{L}^{2}\right)$ as given, let's consider the effect of $\mu$ on

$$
X_{L} / X_{C}=\frac{A_{L}}{A_{C}} \frac{\theta_{a}^{C}\left(\gamma_{C}\right)}{\theta_{a}^{L}\left(\gamma_{L}\right)} \frac{d\left(a_{L}\right)}{\left[d\left(a_{C}\right)-d\left(a_{L}\right)\right]}
$$

We can use the following relationship.

$$
\begin{aligned}
& d\left[\frac{\theta_{a}^{C}\left(\gamma_{C}\right)}{\theta_{a}^{L}\left(\gamma_{L}\right)}\right] / d \mu \\
= & \frac{\theta_{a}^{C}\left(\gamma_{C}\right)}{\theta_{a}^{L}\left(\gamma_{L}\right)}\left[\frac{\theta_{a}^{C^{\prime}}\left(\gamma_{C}\right)}{\theta_{a}^{C}\left(\gamma_{C}\right)}-\frac{\theta_{a}^{L^{\prime}}\left(\gamma_{L}\right)}{\theta_{a}^{L}\left(\gamma_{L}\right)} \lambda_{1}\left(\gamma_{C} ; p_{L}, \frac{A_{C}}{A_{L}}\right)\right] d \gamma_{C} / d \mu \\
= & \frac{\theta_{a}^{C}\left(\gamma_{C}\right)}{\theta_{a}^{L}\left(\gamma_{L}\right)} \frac{\theta_{a}^{L^{\prime}}\left(\gamma_{L}\right)}{\theta_{a}^{L}\left(\gamma_{L}\right)}\left[\frac{\gamma_{L}}{\gamma_{C}} \frac{\frac{\gamma_{C} \theta_{a}^{C^{\prime}}\left(\gamma_{C}\right)}{\theta_{a}^{C}\left(\gamma_{C}\right)}}{\frac{\gamma_{L} \theta_{a}^{L^{\prime}\left(\gamma_{L}\right)}}{\theta_{a}^{L}\left(\gamma_{L}\right)}}-\lambda_{1}\left(\gamma_{C} ; p_{L}, \frac{A_{C}}{A_{L}}\right)\right] d \gamma_{C} / d \mu \\
= & \frac{\theta_{a}^{C}\left(\gamma_{C}\right)}{\theta_{a}^{L}\left(\gamma_{L}\right)} \frac{\theta_{a}^{L^{\prime}}\left(\gamma_{L}\right)}{\theta_{a}^{L}\left(\gamma_{L}\right)}\left[\frac{\lambda\left(\gamma_{C} ; p_{L}, \frac{A_{C}}{A_{L}}\right)}{\gamma_{C}} \frac{\frac{\gamma_{L} \theta_{a}^{L}\left(\gamma_{L}\right)}{\theta_{N}^{L}\left(\gamma_{L}\right)}+1}{\frac{\gamma_{C} \theta_{a}^{C}\left(\gamma_{C}\right)}{\theta_{N}^{C}\left(\gamma_{C}\right)}+1}-\lambda_{1}\left(\gamma_{C} ; p_{L}, \frac{A_{C}}{A_{L}}\right)\right] d \gamma_{C} / d \mu \\
< & \frac{\theta_{a}^{C}\left(\gamma_{C}\right)}{\theta_{a}^{L}\left(\gamma_{L}\right)} \frac{\theta_{a}^{L^{\prime}}\left(\gamma_{L}\right)}{\theta_{a}^{L}\left(\gamma_{L}\right)}\left[\frac{\lambda\left(\gamma_{C} ; p_{L}, \frac{A_{C}}{A_{L}}\right)}{\gamma_{C}}-\lambda_{1}\left(\gamma_{C} ; p_{L}, \frac{A_{C}}{A_{L}}\right)\right] d \gamma_{C} / d \mu<0
\end{aligned}
$$

if $d\left[\lambda\left(\gamma_{C} ; p_{L}, \frac{A_{C}}{A_{L}}\right) / \gamma_{C}\right] / d \gamma_{C}>0$. This relationship is using the fact that

$$
\frac{\gamma_{i} \theta_{a}^{i^{\prime}}}{\theta_{a}^{i}}=-\kappa /\left(\frac{\gamma_{i} \theta_{a}^{i}}{\theta_{N}^{i}}+1\right)
$$

and $d\left[\lambda\left(\gamma_{C} ; p_{L}, \frac{A_{C}}{A_{L}}\right) / \gamma_{C}\right] / d \gamma_{C}>0$ if and only if $\frac{\gamma_{L} \theta_{a}^{L}\left(\gamma_{L}\right)}{\theta_{N}^{L}\left(\gamma_{L}\right)}<\frac{\gamma_{C} \theta_{a}^{C}\left(\gamma_{C}\right)}{\theta_{N}^{C}\left(\gamma_{C}\right)}$. Similarly, we obtain

$$
\begin{aligned}
& d\left(\frac{d\left(a_{C}\right)}{d\left(a_{L}\right)}\right) / d \mu \\
= & \frac{d\left(a_{C}\right)}{d\left(a_{L}\right)}\left[\frac{\left(a_{C}\right)^{2} g\left(a_{C}\right) / \gamma_{C}}{d\left(a_{C}\right)}-\frac{\left(a_{L}\right)^{2} g\left(a_{L}\right) / \gamma_{L}}{d\left(a_{L}\right)} \lambda_{1}\left(\gamma_{C}, p_{L}\right)\right] d \gamma_{C} / d \mu \\
> & \frac{d\left(a_{C}\right)}{d\left(a_{L}\right)} \frac{\left(a_{L}\right)^{2} g\left(a_{L}\right) / \gamma_{L}}{d\left(a_{L}\right)}\left[\frac{\lambda\left(\gamma_{C} ; p_{L}, \frac{A_{C}}{A_{L}}\right)}{\gamma_{C}}-\lambda_{1}\left(\gamma_{C} ; p_{L}, \frac{A_{C}}{A_{L}}\right)\right] d \gamma_{C} / d \mu>0
\end{aligned}
$$

if $d\left[\lambda\left(\gamma_{C} ; p_{L}, \frac{A_{C}}{A_{L}}\right) / \gamma_{C}\right] / d \gamma_{C}>0$. This is using the assumption that $\frac{a^{2} g(a)}{d(a)}$ is increasing in $a$. This implies that

$$
d\left(X_{L} / X_{C}\right) / d \mu<0 .
$$


for $p_{L} \in\left[p_{L}^{2}, p_{L}^{1}\right)$ if $\kappa \geq 1-\frac{\log \left[\frac{k_{C}}{k_{L}}\right]}{\log \left[\frac{m_{L}}{m_{C}}\right]}$ and for $p_{L} \in\left[p_{L}^{2}, A_{C} / A_{L}\right)$ if $0 \leq \kappa<$ $1-\frac{\log \left[\frac{k_{C}}{k_{L}}\right]}{\log \left[\frac{m_{L}}{m_{C}}\right]}$.

\section{Step 4}

Next suppose $p_{L} \in\left(p_{L}^{2}, p_{L}^{3}\right) \cdot \gamma_{L}=\gamma_{C}=\gamma^{*}$ is determined by

$$
p_{L}=\left(\frac{A_{C}}{A_{L}}\right) \frac{\theta_{N}^{L}\left(\gamma^{*}\right)+\gamma^{*} \theta_{a}^{L}\left(\gamma^{*}\right)}{\theta_{N}^{C}\left(\gamma^{*}\right)+\gamma^{*} \theta_{a}^{C}\left(\gamma^{*}\right)} .
$$

$\gamma^{*}$ is independent of $\mu$. This means that $d \gamma^{*} / d \mu=0$. We have only the direct effect of $\mu$ on $X_{L} / X_{C}$, which is negative.

From step 3 and this step, this completes the proof of (i) and the first half of (ii) in the proposition.

\section{Step 5}

Finally let us show the last part of (ii). Suppose that there does not exist $\bar{p}_{L} \in\left(A_{C} / A_{L}, p_{L}^{1}\right)$ so that $X_{L} / X_{C}$ is increasing in $\mu$ for any $p \in\left(\bar{p}_{L}, p_{L}^{1}\right)$. Then $p_{L}^{1}$ has to be non-decreasing in $\mu$. However

$d p_{L}^{1} / d \mu=\left(p_{L}^{1} / \gamma_{C}^{1}\right)\left[\frac{\frac{m_{L}}{m_{C}} \gamma_{C}^{1} \theta_{a}^{L}\left(\frac{m_{L}}{m_{C}} \gamma_{C}^{1}\right)}{\theta_{N}^{L}\left(\frac{m_{L}}{m_{C}} \gamma_{C}^{1}\right)+\frac{m_{L}}{m_{C}} \gamma_{C}^{1} \theta_{a}^{L}\left(\frac{m_{L}}{m_{C}} \gamma_{C}^{1}\right)}-\frac{\gamma_{C}^{1} \theta_{a}^{C}\left(\gamma_{C}^{1}\right)}{\theta_{N}^{C}\left(\gamma_{C}^{1}\right)+\gamma_{C}^{1} \theta_{a}^{C}\left(\gamma_{C}^{1}\right)}\right] d \gamma_{C}^{1} / d \mu$

is negative from step 2(ii). This is the contradiction.

Proof of Proposition 7

Let the indirect utility function for country $j$ be $V\left(p_{L}^{j}, I^{j}\right)$ where national income

$$
I^{j}=p_{L}^{j} X_{L}^{j}+X_{C}^{j}
$$

By Roy's identity $D_{L}^{j}=-\frac{V_{p}\left(p_{L}^{j}, I^{j}\right)}{V_{I}\left(p_{L}^{j}, I^{j}\right)}$,

$$
\begin{aligned}
& d V\left(p_{L}^{j}, I^{j}\right) / d p_{L}^{j}=\frac{\partial V\left(p_{L}^{j}, I^{j}\right)}{\partial p_{L}^{j}}+\frac{\partial V\left(p_{L}^{j}, I^{j}\right)}{\partial I^{j}} \frac{d I^{j}}{d p_{L}^{j}} \\
= & \frac{\partial V\left(p_{L}^{j}, I^{j}\right)}{\partial I^{j}}\left[-D_{L}^{j}+\frac{d I^{j}}{d p_{L}^{j}}\right] \\
= & \frac{\partial V\left(p_{L}^{j}, I^{j}\right)}{\partial I^{j}}\left[\left(X_{L}^{j}-D_{L}^{j}\right)+p_{L}^{j} d X_{L}^{j} / d p_{L}^{j}+d X_{C}^{j} / d p_{L}^{j}\right]
\end{aligned}
$$


Since $\frac{\partial V\left(p_{L}^{j}, I^{j}\right)}{\partial I^{j}}>0$, the sign of the welfare effect of the change in $p_{L}^{j}$ is the same as the sign of

$$
\left(X_{L}^{j}-D_{L}^{j}\right)+p_{L}^{j} d X_{L}^{j} / d p_{L}^{j}+d X_{C}^{j} / d p_{L}^{j}
$$

Owing to linear homogeneity of the production function and the common $N_{L} / a$ chosen by all entrepreneurs in a given sector, $X_{L}^{j}=A_{L} F_{L}\left(N_{L}^{j}, H_{L}^{j}\right)$ where $N_{L}^{j}$ (resp. $H_{L}^{j}$ ) is the total amount of unskilled (resp. skilled) labor used in the $L$ sector of country $j$. Since $p_{L}^{j} d X_{L}^{j} / d N_{L}^{j}=w^{j}$ and $\gamma_{L}^{j}=$ $\frac{\partial F_{L}\left(N_{L}^{j}, H_{L}^{j}\right) / \partial H_{L}^{j}}{\partial F_{L}\left(N_{L}^{j}, H_{L}^{j}\right) / \partial N_{L}^{j}}$

$$
\begin{aligned}
& p_{L}^{j} d X_{L}^{j} / d p_{L}^{j}=p_{L}^{j} A_{L}\left[\partial F_{L}\left(N_{L}^{j}, H_{L}^{j}\right) / \partial N_{L}^{j}\left[d N_{L}^{j} / d p_{L}^{j}\right]+\partial F_{L}\left(N_{L}^{j}, H_{L}^{j}\right) / \partial H_{L}^{j}\left[d H_{L}^{j} / d p_{L}^{j}\right]\right] \\
= & w^{j}\left[d N_{L}^{j} / d p_{L}^{j}+\gamma_{L}^{j} d H_{L}^{j} / d p_{L}^{j}\right]
\end{aligned}
$$

Similarly

$$
\begin{aligned}
& d X_{C}^{j} / d p_{L}^{j}=A_{C}\left[\partial F_{C}\left(N_{C}^{j}, H_{C}^{j}\right) / \partial N_{C}^{j}\left[d N_{C}^{j} / d p_{L}^{j}\right]+\partial F_{C}\left(N_{C}^{j}, H_{C}^{j}\right) / \partial H_{C}^{j}\left[d H_{C}^{j} / d p_{L}^{j}\right]\right] \\
= & w^{j}\left[d N_{C}^{j} / d p_{L}^{j}+\gamma_{C}^{j} d H_{C}^{j} / d p_{L}^{j}\right]
\end{aligned}
$$

Therefore

$p_{L}^{j} d X_{L}^{j} / d p_{L}^{j}+d X_{C}^{j} / d p_{L}^{j}=w^{j}\left[d\left(N_{L}^{j}+N_{C}^{j}\right) / d p_{L}^{j}+\gamma_{C}^{j} d\left(H_{L}^{j}+H_{C}^{j}\right) / d p_{L}^{j}+\left(\gamma_{L}^{j}-\gamma_{C}^{j}\right) d H_{L}^{j} / d p_{L}^{j}\right]$.

Since $H_{L}^{j}=\mu d\left(a_{L}^{j}\right)$ for $p_{L}^{j} \in\left(p_{L}^{j 2}, p_{L}^{j 1}\right)$ and $\gamma_{L}^{j}=\gamma_{C}^{j}$ for $p_{L}^{j} \in\left(p_{L}^{j 3}, p_{L}^{j 2}\right)$,

$$
\left(\gamma_{L}^{j}-\gamma_{C}^{j}\right) d H_{L}^{j} / d p_{L}^{j}=\mu\left(\gamma_{L}^{j}-\gamma_{C}^{j}\right) d\left(d\left(a_{L}^{j}\right)\right) / d p_{L}^{j}
$$

holds for $p_{L}^{j} \in\left(p_{L}^{j 3}, p_{L}^{j 1}\right)$. With $N_{L}^{j}+N_{C}^{j}=\mu G\left(a_{C}^{j}\right)+(1-\mu)$ and $H_{L}^{j}+H_{C}^{j}=$ $\mu d\left(a_{C}^{j}\right)$ for $p_{L}^{j} \in\left(p_{L}^{j 3}, p_{L}^{j 1}\right)$,

$$
\begin{aligned}
& \left(X_{L}^{j}-D_{L}^{j}\right)+p_{L}^{j} d X_{L}^{j} / d p_{L}^{j}+d X_{C}^{j} / d p_{L}^{j} \\
= & \left(X_{L}^{j}-D_{L}^{j}\right)+w^{j} \mu\left[d G\left(a_{C}^{j}\right) / d p_{L}^{j}+\gamma_{C}^{j} d\left(d\left(a_{C}^{j}\right)\right) / d p_{L}^{j}+\left(\gamma_{L}^{j}-\gamma_{C}^{j}\right) d\left(d\left(a_{L}^{j}\right)\right) / d p_{L}^{j}\right] \\
= & \left(X_{L}^{j}-D_{L}^{j}\right)+w^{j} \mu\left[\left(1-m_{C}\right) g\left(a_{C}^{j}\right) d a_{C}^{j} / d p_{L}^{j}-\left(\gamma_{L}^{j}-\gamma_{C}^{j}\right) a_{L}^{j} g\left(a_{L}^{j}\right) d a_{L}^{j} / d p_{L}^{j}\right]
\end{aligned}
$$




\section{KEIO ECONOMIC SOCIETY \\ DISCUSSION PAPER SERIES}

No. 08-1 (2008) Hideo Akabayashi and Michio Naoi "Does the Public Sector Crowd Out the Private Sector in the Higher Education Market?: Theory and Evidence from Japan”, 20 pages.

No. 08-2 (2008) 寺出道雄「比例と均衡一「経済表＼cjkstart範式」再考一」、20 pages.

No. 09-1 (2009) Michio Naoi, Miki Seko and Kazuto Sumita “Community Rating, Cross Subsidies and Underinsurance: Shy So Many Households in Japan Do Not Purchase Earthquake Insurance”, 25 pages.

No. 09-2 (2009) Michio Naoi, Miki Seko and Kazuto Sumita “Earthquake Risk and Housing Prices in Japan: Evidence Before and After Massive Earthquakes”, 30 pages.

No. 09-3 (2009) Miki Seko, Kazuto Sumita and Michio Naoi, "Residential Mobility Decision in Japan: Identifying the Effects of Housing Equity Constraints and Income Shocks under the Recourse Loan System”, 24 pages.

No. 09-4 (2009) Takuji Arai, “Convex Risk Measures on Orlicz Spaces: Convolution and Shortfall”, 18 pages.

No. 10-1 (2010) Mikio Ito and Akihiko Noda, “Information Criteria for Moment Restriction Models: An Application of Empirical Cressie-Read Estimator for CCAPM”, 17 pages.

No. 10-2 (2010) 寺出道雄 <資料紹介>「日本共産党運動年表比例と均衡」文部省思想局 刊行資料への共産党関係者による書き込み本、25 pages.

No. 10-3 (2010) 寺出道雄「植物の再生産表式 一門司正三再読一」、17 pages.

No. 10-4 (2010) Pranab Bardhan, Dilip Mookherjee and Masatoshi Tsumagari, "Middlemen Margins and Globalization”, 57 pages 
No. 08-1 (2008) Hideo Akabayashi and Michio Naoi “Does the Public Sector Crowd Out the Private Sector in the Higher Education Market?: Theory and Evidence from Japan”, 20 pages.

No. 08-2 (2008) 寺出道雄「比例と均衡一「経済表＼cjkstart範式」再考一」、20 pages.

No. 09-1 (2009) Michio Naoi, Miki Seko and Kazuto Sumita “Community Rating, Cross Subsidies and Underinsurance: Shy So Many Households in Japan Do Not Purchase Earthquake Insurance”, 25 pages.

No. 09-2 (2009) Michio Naoi, Miki Seko and Kazuto Sumita "Earthquake Risk and Housing Prices in Japan: Evidence Before and After Massive Earthquakes”, 30 pages.

No. 09-3 (2009) Miki Seko, Kazuto Sumita and Michio Naoi, “Residential Mobility Decision in Japan: Identifying the Effects of Housing Equity Constraints and Income Shocks under the Recourse Loan System”, 24 pages.

No. 09-4 (2009) Takuji Arai, “Convex Risk Measures on Orlicz Spaces: Convolution and Shortfall”, 18 pages.

No. 10-1 (2010) Mikio Ito and Akihiko Noda, "Information Criteria for Moment Restriction Models: An Application of Empirical Cressie-Read Estimator for CCAPM”, 17 pages.

No. 10-2 (2010) 寺出道雄 ＜資料紹介>「日本共産党運動年表比例と均衡」文部省思想局 刊行資料への共産党関係者による書き込み本、25 pages.

No. 10-3 (2010) 寺出道雄「植物の再生産表式 一門司正三再読一」、17 pages.

No. 10-4 (2010) Pranab Bardhan, Dilip Mookherjee and Masatoshi Tsumagari, "Middlemen Margins and Globalization”, 57 pages 